\title{
Dual Economies and International Total Factor Productivity Differences: Channelling the Impact from Institutions, Trade, and Geography
}

\author{
By Areendam Chanda $\dagger$ and CARL-Johan DalgaARd $\ddagger$ \\ $\dagger$ Louisiana State University $\quad \ddagger$ University of Copenhagen and EPRU
}

Final version received 12 June 2007.

\begin{abstract}
This paper provides a framework that decomposes aggregate total factor productivity (TFP) into a component reflecting relative efficiency across sectors, and another component that reflects the absolute level of efficiency. A development accounting analysis suggests that as much as $85 \%$ of the international variation in aggregate $T F P$ can be attributed to variation in relative efficiency across sectors. Estimation results show that recent findings highlighting the importance of strong protection of property rights, financial development and geographical advantage for the level of $T F P$, can be explained by their impact on relative efficiency.
\end{abstract}

It is certainly unwise to suggest that all economies are equally efficient at reallocating inputs across sectors. This difference will be reflected in $A(t)$, and maybe not only there ... the nontechnological sources of differences in TFP may be more important than the technological ones. Indeed, they may control the technological ones, especially in developing countries.

-Robert Solow (2001, pp. 285, 287)

\section{INTRODUCTION}

The problem of economic development is often viewed as a problem of structural change. For economists such as William Arthur Lewis, the central problem of development was to be solved by ensuring that agriculture continued to maintain its production levels while workers moved to the nascent industrial sector. In a similar vein, other classical theories of economic development such as the Stages of Economic Growth (Rostow 1961), the Big Push (Rosenstein-Rodan 1943) and the Critical Minimum Effort Thesis (Leibenstein 1960) essentially viewed the problem as one of poor countries being stuck in a poverty trap characterized by a backward agricultural sector, and the challenge being one of ensuring a transition to modern industrial production. ${ }^{1}$

More recently, development accounting exercises have increasingly provided evidence that differences in living standards can be overwhelmingly accounted for by differences in total factor productivity $(T F P)$, and not by differences in the stocks of raw labour, human capital and physical capital. Klenow and Rodriguez-Clare (1997) and Hall and Jones (1999) were the initial studies suggesting that differences in TFP might account for more than $60 \%$ of the differences in output per worker. Not surprisingly, this has led to an increasing focus on explaining differences in $T F P$, often taken to mean technology or efficiency, rather than factor accumulation.

Finally, another strand of the recent growth and development literature, which might be put under the heading 'fundamental determinants of long run productivity', has also provided strong empirical evidence emphasizing the importance of factors such as institutional quality, openness to international trade and geographic circumstances. Well 
known contributions in this literature include Hall and Jones (1999), Acemoglu et al. (2001, 2002), Easterly and Levine (2003) and Alcála and Ciccone (2004), among others.

In this paper we attempt to build a bridge between these recent developments and the more longstanding view that aggregate productivity is intimately related to the process of structural change. To achieve this end, we begin by undertaking a novel accounting exercise. The approach builds on a relatively mild assumption beyond what is standard in the literature on development accounting. We assume a Cobb-Douglas production function for the non-agricultural sector of the economy. On this basis we demonstrate how aggregate TFP levels, obtained using the standard cross-country development accounting methodology, can be further decomposed into a component that captures intersectoral (or relative) efficiency and the absolute level of efficiency in the economy; the latter is measured by the level of TFP in the non-agricultural sector. The key finding is that variation in relative efficiency across sectors (agriculture $v$. non-agriculture) can explain as much as $85 \%$ of the differences in aggregate TFP across countries.

Relative efficiency between sectors is affected mainly by two factors. The first is the allocation of inputs across sectors. Relative efficiency will suffer if the allocation of physical and human capital is inhibited by frictions of various kinds, which keeps marginal products from being equalized. The second influence is from variations in the relative level of technology in the two sectors across countries, which could be generated by different rates of technology adoption. Thus, the large variation in the component reflecting relative efficiency should not be taken to imply that technological differences (necessarilly) are of second-order importance. However, what this finding does indicate is that levels of TFP are highly affected by the degree of efficiency of the process of structural change that is taking place-consistent with the classical approach to development economics cited above. By extension, our results also suggest that a reasonable theory of aggregate TFP differences should be based on a two-sector approach.

In the second half of this paper we investigate what might explain the variation in relative efficiency that we observe across countries. Inspired by the recent literature on the role of institutions, trade and geography, we undertake econometric exercises that allow us to gauge the role that these variables play in explaining the influence from 'composition' on aggregate TFP, as opposed to the absolute level of non-agricultural TFP.

Our estimates overwhelmingly suggest that the beneficial effects that institutions, geography and to some extend trade seem to have on aggregate TFP is channelled primarily through relative efficiency. In contrast, none of the three determinants affects the left-over residual (non-agricultural TFP). These results are robust to a careful treatment of issues of simultaneity bias, country coverage, different measures of institutions, geography and trade, and to different choices of instrumental variables. In particular, we explore the role of institutions not only by examining broad measures of institutional quality but also with more specific measures, such as the risk of expropriation, legal complexity and financial market development. Overall, our sharp conclusions regarding the role of relative efficiency versus absolute efficiency remain surprisingly robust.

The present paper is related to the literature on development accounting that was pioneered by Krueger (1968) and King and Levine (1994), and recently reviewed in Caselli (2005). However, in our work we attempt to move beyond the standard approach where GDP is generated by combining aggregate stocks of capital (human and physical) and an index of technology in a neoclassical (typically, Cobb-Douglas) production 
function. In abandoning what is essentially a one-sector approach, this paper is also related to a literature that has started to re-examine the implications of dual economy considerations for long-run productivity. A number of recent contributions have examined the aggregate consequences of misallocation of inputs resulting from, barriers to capital accumulation (Restuccia 2004), imperfections in factor markets (Vollrath 2006), home production (Gollin et al. 2004), the role of fixed costs (Banerjee and Duflo 2005) and externalities leading to multiple equilibria (Graham and Temple 2006). ${ }^{2}$

The contributions most directly related to our accounting work are those of Caselli (2005), Vollrath (2006) and Cordoba and Ripoll (2006). They also provide a development-accounting analysis of the importance of intersectoral allocations of input across agriculture and non-agricultural sectors of the economy. Their methodologies can be viewed as a 'bottom-up' approach to the issue at hand, which consists of specifying disaggregated production functions (in agriculture and outside agriculture) upon which static counterfactuals are performed so as to assess the importance of intersectoral differences in technology (or TFP), capital-output ratios, etc., for aggregate labour productivity. In contrast, our methodology can be viewed as a 'top-down' approach to the issue of how intersectoral allocations matter for aggregate TFP differences. The key distinguishing feature in the two approaches lies in the fact that we do not make assumptions about the nature of the underlying production technology in agriculture. The main advantages are that this dispenses with the need to make assumptions regarding inputs and factor intensities in the agricultural production function, which remains a somewhat controversial issue. Indeed, this differentiates our work from all of the above-referred papers. Further, we do not need to impose any $a$ priori conditions regarding the efficiency of factor market allocations. ${ }^{3}$ Of course, the drawback of our approach is that it cannot distinguish between technological and nontechnological sources of relative efficiency, whereas this is feasible under the approach followed by Caselli, Vollrath, and Cordoba and Ripoll. In this sense, our decomposition exercise complements theirs.

Our regression analysis is related to the literature on fundamental determinants of productivity, mentioned above. Previous work has documented a causal impact from e.g. institutions and trade on TFP (Hall and Jones 1999; Alcalá and Ciccone 2004). The present paper goes a step further and documents that this finding can be explained by the impact of institutions, geography and to some extent trade on the efficiency of the economy through the dual economy channel. That is, institutions, geography and trade emerge as causal determinants, at a deeper level, of relative efficiency levels across sectors.

Overall, the present paper can be viewed as providing an assessment of the scope for intersectoral differences (attributable to underlying sources such as those mentioned above) to explain differences in aggregate productivity. Our findings, while not placing one of the above-mentioned approaches above another, suggests that a strong case can be made in favour of theories for aggregate TFP differences that are grounded in dual economy type frameworks. Moreover, our work suggests that a critical manifestation of strong institutions - protection of property rights and financial development in particular - is that they ensure a high level of aggregate efficiency through intersectoral allocations.

\section{ACCOUNTING}

This section is in four parts. Section (a) develops the formula needed for our decompositions, and Section (b) provides a brief digression on the interpretation 
of the accounting expression. Section (c) discusses data and Section (d) presents our results.

\section{(a) Intersectoral influences on aggregate TFP}

In order to decompose $T F P$, we begin by observing that GDP per worker, $Y / L$ can be written

$$
\frac{Y}{L}=\left(\frac{Y / L}{Y_{n a} / L_{n a}}\right)\left(\frac{Y_{n a}}{L_{n a}}\right)
$$

where $Y_{n a} / L_{n a}$ is labour productivity in the non-agricultural sector. The first term on the RHS $\left((Y / L) /\left(Y_{n a} / L_{n a}\right)\right)$, conveys information about relative efficiency between sectors. Obviously, if the agricultural sector and the non-agricultural sector are equally productive, this term is 1 . Notice also that the term $Y_{n a} / L_{n a}$ then captures the absolute level of labour productivity in the economy, as measured by labour productivity outside agriculture.

In order to proceed further, we need to impose some additional structure. Hence our key assumption is that the non-agricultural sector is characterized by a Cobb-Douglas constant returns-to-scale production function with capital and human-capital augmented labour as inputs and a labour-augmenting TFP parameter:

$$
\frac{Y_{n a}}{L_{n a}}=\left(\frac{K_{n a}}{Y_{n a}}\right)^{\alpha /(1-\alpha)} h_{n a} A_{n a} .
$$

Upon substitution into equation (1), we can now express real GDP per worker as

$$
\frac{Y}{L}=\left(\frac{\left[\left(K_{n a} / Y_{n a}\right) /(K / Y)\right]^{\alpha /(1-\alpha)}\left(h_{n a} / h\right)}{\left(Y_{n a} / L_{n a}\right) /(Y / L)}\right) A_{n a}\left(\frac{K}{Y}\right)^{\alpha /(1-\alpha)} h .
$$

Now consider the standard decomposition of aggregate labour productivity, which has become popular in the literature. Assuming the existence of an aggregate CobbDouglas production function, such an exercise consists of decomposing GDP per worker, $Y / L$, into contributions stemming from capital input, human capital and a residual $(T F P)$ :

$$
\frac{Y}{L}=\operatorname{TFP}\left(\frac{K}{Y}\right)^{\alpha /(1-\alpha)} h
$$

The correspondence between our equation (2) and the aggregate TFP component is then obvious:

$$
\operatorname{TFP}=\left(\frac{\left[\left(K_{n a} / Y_{n a}\right) /(K / Y)\right]^{\alpha /(1-\alpha)}\left(h_{n a} / h\right)}{\left(Y_{n a} / L_{n a}\right) /(Y / L)}\right) A_{n a} .
$$

This suggests that the numbers calculated by e.g. Klenow and Rodriguez-Clare (1997) and Hall and Jones (1999) may confound the absolute level of efficiency in the economy, as represented by $A_{n a}$, and the relative efficiency across sectors, represented by the somewhat complicated term in large parentheses. These considerations induce us to split equation (4) into two parts:

$$
T F P=C O M P \times A_{n a},
$$

(C) The London School of Economics and Political Science 2008 
where $C O M P$, or what we refer to as the 'composition term', is

$$
C O M P=\left(\frac{\left[\left(K_{n a} / Y_{n a}\right) /(K / Y)\right]^{\alpha /(1-\alpha)}\left(h_{n a} / h\right)}{\left(Y_{n a} / L_{n a}\right) /(Y / L)}\right) .
$$

Below, we examine how much of the variation in the Hall and Jones TFP can be accounted for by $C O M P$ and $A_{n a}$ respectively. Whereas $A_{n a}$ represents the level of efficiency in the economy, as measured by TFP in the non-agricultural sector, COMP captures relative efficiency across sectors. To see this more clearly, note that $C O M P$ can be rearranged as

$$
C O M P=\left(\frac{\left[\left(K_{n a} / Y_{n a}\right) /(K / Y)\right]^{\alpha /(1-\alpha)}\left(h_{n a} L_{n a} / h L\right)}{\left(Y_{n a} / Y\right)}\right) .
$$

Written this way, the numerator reflects the allocation of all factors, while the denominator reflects the relative output levels. Trivially, both the numerator and the denominator would collapse to 1 in a single-sector economy. Alternatively, it would also collapse to 1 if there are two sectors but the factor allocations and output composition are completely aligned (e.g. if $20 \%$ of capital and labour is devoted to the sector that is responsible for $20 \%$ of the output). In other words, if both sectors are equally efficient in converting physical inputs into output, COMP becomes 1 .

While the split between $A_{n a}$ and COMP should be conceptually clear-one captures the absolute level of efficiency, the other relative efficiency across sectors-one may still wonder which factors determine $C O M P$, at a deeper level. This issue is discussed in the next subsection.

\section{(b) Interpretations}

In order to understand the decomposition implied by equations (5) and (6), consider as a benchmark the following caricature of a closed economy. Suppose preferences are defined over two goods (which are produced in different sectors). The market for both goods is competitive, and all factor markets are competitive. There are two inputs in the economy: capital and labour. Finally, suppose both sectors have identical Cobb-Douglas production functions: $Y=A K_{i}^{\alpha} L_{i}^{1-\alpha}, i=1,2$. In this case both sectors will exhibit the same factor intensity, $K_{1} / L_{1}=K_{2} / L_{2}=K / L$, where $K=K_{1}+K_{2}, L=L_{1}+L_{2}$. Next, define real GDP as

$$
Y=Y_{1}+p Y_{2}
$$

where $p$ is the relative price of good 2 in terms of good 1. On this basis we can show that GDP can be written

$$
Y=A K^{\alpha} L^{1-\alpha} \text {. }
$$

This is the exact aggregate production function. It holds the property that output is maximized given total available capital and labour, and holds the same properties of the corresponding microeconomic (sector-specific) production functions. Essentially, it is an illustration of the aggregation theorem due to Fisher (1978). Also, $A$ is, in fact, the common level of productivity across sectors.

Now, if this indeed is a reasonable description of real-world economies, it is clear that TFP in the standard development accounting exercise identifies the level of 'technology'. As a result, the term labelled $C O M P$ in equation (6) should reduce to 1 . Analytically, we 
can easily confirm that this must be the case. Since both sectors have identical production functions, levels of technology and choose identical factor intensities, relative labour productivity must equal 1, and the ratio between GDP per worker and average labour productivity in the non-agricultural sector is therefore 1. By extension, in light of the identical factor intensities and average labour productivity, relative capital intensity $\left(K_{n a}\right)$ $\left.Y_{n a}\right) /(K / Y)$ equals 1 . This leaves human capital input in equation (6), which we omitted from the present example. But, by the homogeniety of $A$, assumption, $h_{n a} / h$ would be 1 as well. $^{4}$

However, this picture is unlikely to reflect reality. As soon as we deviate from the above set of restrictive assumptions, exact aggregation is no longer feasible. ${ }^{5}$ That is, we will still be able to write output in the form $Y=E K^{\alpha} L^{1-\alpha}$, but $E$ would now reflect the imposed complications. To illustrate, suppose we add a friction to the labour market that prevents wages from being fully equalized: $w_{2}=\pi w_{1}, \pi<1$; in all other respects, however, we maintain the previous assumptions. The distortion in the labour market means that unit costs are not the same in the two sectors, so $p=\pi^{1-\alpha}$. Moreover, factor intensity in the two sectors fulfil $\pi k_{1}=k_{2}$. It can now be shown that aggregate real GDP can be written as

$$
Y=A\left[\left(\frac{k_{1}}{k}\right)^{\alpha}\left[\pi+(1-\pi) \lambda_{1}\right]\right] K^{\alpha} L^{1-\alpha},
$$

where $\lambda_{1}$ is the share of employment in sector 1 . Clearly, the term in small brackets is smaller than 1 . The point is that conventionally measured aggregate TFP no longer uniquely captures $A$. In this particular case, $C O M P$ reflects $\left\{\left(k_{1} / k\right)^{\alpha}\left[\pi+(1-\pi) \lambda_{1}\right]\right\}$ if we put $A=A_{n a}{ }^{6}{ }^{6}$ The interpretation of differences in COMP in this case would be that some countries are less distorted that others. For given $\pi$, the output loss is larger if $\lambda_{1}$ declines (which in turn would depend on demand considerations).

Of course, other cases can be imagined. For example, if levels of $A$ differ across sectors as well, this would also influence the COMP term. Similarly, if the production functions differ with respect to input intensities, or to the nature of the inputs, such differences would affect $C O M P$ too. This means that $C O M P$ becomes an expression that captures relative sectoral efficiencies driven by the (mis)allocation of factors and/or technological differences.

All of this makes the COMP term worth exploring further, in that it allows us to assess the scope of the body of theories explaining aggregate productivity differences arising from variations in relative levels of productivity across sectors, or by frictions in factor markets. If the actual variation in COMP is small, one would have to be less confident that such mechanisms are important as foundations for a theory of aggregate TFP differences.

\section{(c) Data}

While the basic accounting equation may seem straightforward, data pose a challenge. The main concern is obviously that of international comparability. Specifically, internationally comparable data at the sectoral level is required. In addition, we need intersectoral capital-output ratios, and intersectoral human capital levels. In the rest of this section we discuss how we try to overcome these obstacles.

To begin, we need aggregate TFP numbers. Since PPP value added for agriculture is available only for 1985 (as explained below), our accounting exercise will be for 1985. In

(C) The London School of Economics and Political Science 2008 
performing the basic development accounting analysis, we follow Hall and Jones (1999) (henceforth HJ). As HJ considered 1988, we have to redo their calculations. HJ used 1985 for average human capital in the economy, so this bit of input data remains the same. The capital-output ratios for 1985 were calculated by replicating the HJ methodology exactly. Finally, invoking data on real GDP per worker from PWT version 5.6, we calculate $T F P$ for 1985 as the residual in equation (3). ${ }^{7}$ Below, we refer to these numbers as $H J-T F P^{8}{ }^{8}$

To further decompose TFP, we need PPP numbers on labour productivity outside agriculture. We obtain these by first deriving PPP shares of agriculture value added in GDP; with such numbers in hand we can obtain PPP shares of non-agriculture value added in GDP using PPP GDP numbers from Penn World Tables (PWT). Subseqently average labour productivity in the non-agricultural sector, $Y_{n a} / L_{n a}$, can be calculated using labour employment share data from World Development Indicators (WDI).

FAO constructs a set of international prices on agricultural commodities at an annual frequency, which Rao (1993) used to construct cross-country data on agriculture value added, though only for $1985 .{ }^{9}$ It would seem that by combining Rao's work with data from PWT we would obtain the shares we need for 1985. As Caselli (2005) observes, however, the FAO numbers cannot readily be subtracted from aggregate PWT numbers in 1985 to get PPP value added for the rest of the economy. This is because, while PPP data for aggregate prices are normalized to 1 for the United States in the PWT, PPP data for agricultural prices are normalized to 1 for the United States in the FAO data. Of course, nothing guarantees that the implicit PWT PPP exchange rate for agriculture should be 1; accordingly, we need to renormalize the FAO numbers. The details of this are laid out in the Appendix.

This still leaves us with $\left[\left(K_{n a} / Y_{n a}\right) /(K / Y)\right]^{\alpha /(1-\alpha)}$ and $h_{n a} / h$-the allocations of capital and human capital. There has been some progress towards estimating the stock of physical capital in the agricultural sector. In particular, Crego et al. (2000) have estimated the fixed capital stock in agriculture for 62 countries for various years covering the period 1967-92. In addition to fixed capital stocks in agriculture, they also estimated fixed capital stocks in manufacturing and the entire economy. ${ }^{10}$ Since their estimates are calculated independently from ours (and hence also of $\mathrm{HJ}$ ), it is easy to compare the reliability of their data, at least for the aggregate measures. A simple correlation between the two data-sets for the year 1985 produces a correlation of 0.95 for a sample of 53 countries; and a regression (with the constant suppressed) of the Crego et al. numbers on our numbers yield a coefficient of 0.93 . Figure 1 plots the logarithm of aggregate fixed capital per worker for both the series. The similarity between the two series is quite obvious. We calculate the stock of non-agricultural capital $\left(K_{n a}\right)$ by subtracting their values of agricultural fixed capital from their values of aggregate fixed capital.

Human capital numbers at the sectoral level are even more sparse than the physical capital numbers. However, there has been some progress in this sphere too. In particular, Vollrath (2006), building upon the work of Timmer (2002), has compiled data on years of schooling in rural and urban areas by country. Ulubaşoğlu and Cardak (2007) have also compiled similar data using UNESCO Education Yearbooks. To the extent that rural and urban years of schooling adequately capture agricultural and non-agricultural differences, this is the best that is available. Here we use Vollrath's numbers for 1985 and supplement them with those of Ulubasoglu and Cardak's measures for additional countries for which there is an observation in the 1980s. Even then, our sample is limited to only 40 countries. ${ }^{11}$

(C) The London School of Economics and Political Science 2008 


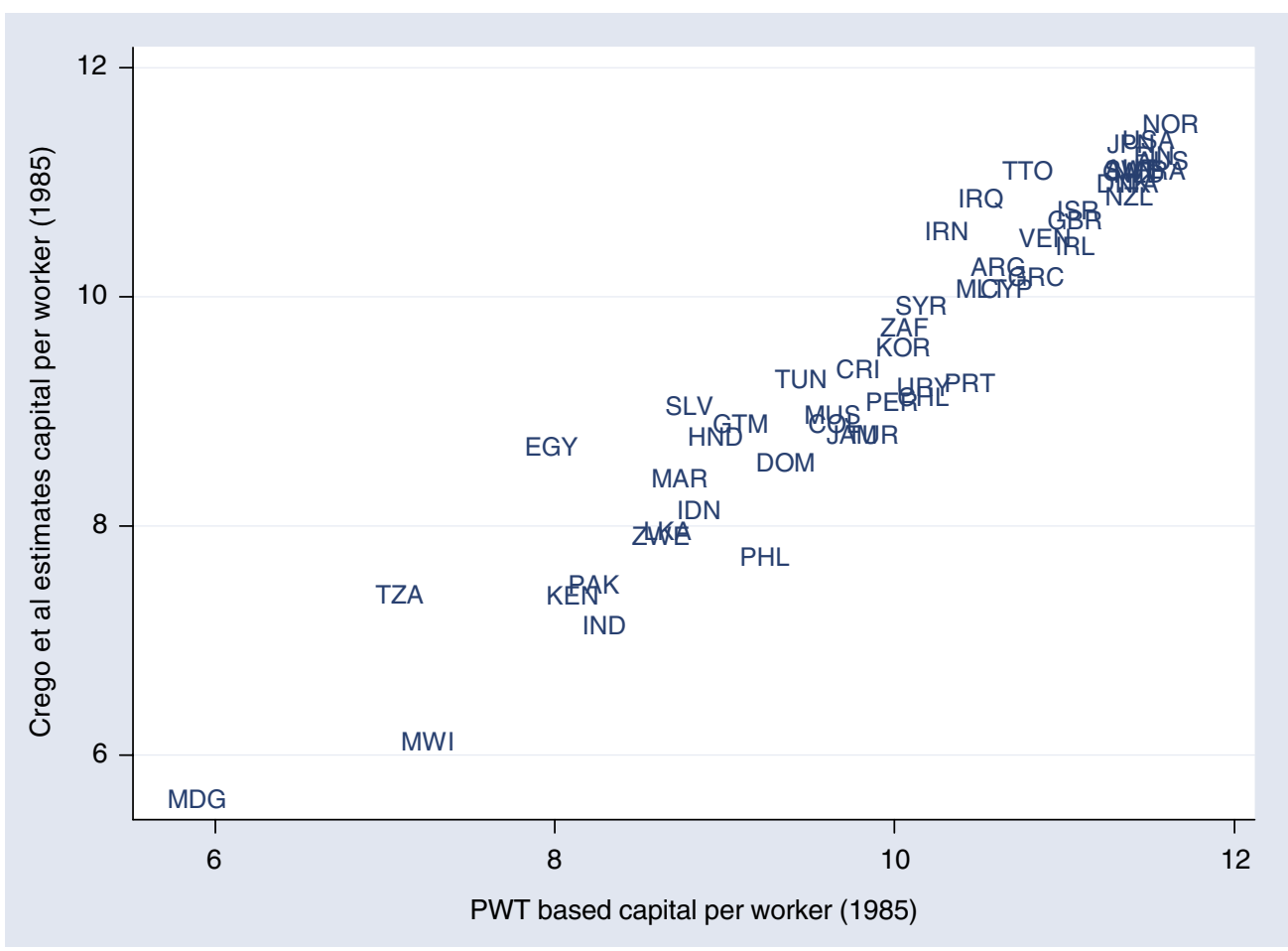

FIGURE 1. Comparing capital per worker estimates (1985).

In the development-accounting literature, the widely adopted practice is now to use microeconomic-based Mincerian returns and combine them with estimates of schooling years. What this implies is that the average human capital per worker can be calculated using a formula such as

$$
h=\exp \left(\phi_{p} s_{p}+\phi_{s} s_{s}+\phi_{\tau} s_{\tau}\right)
$$

where $\phi_{p}, \phi_{s}$ and $\phi_{\tau}$ are the Mincerian returns to an additional year of schooling at primary, secondary and higher levels, whereas $s_{p}, s_{s}$ and $s_{\tau}$ represent the average years of schooling for each sector at each of these levels. This is the approach followed by HJ for the economy as a whole. Since we have applied their human capital numbers to calculate aggregate TFP, we stick with this approach. In particular, the first four years of schooling are allocated to primary schooling, the next four years to secondary and the rest to tertiary for both sectors. For returns to education at the various levels of schooling, HJ assume $13.4 \%$ for primary, $10.6 \%$ for secondary and $6.8 \%$ for primary. However these too are for the economy as a whole. If collecting sectoral data on years of schooling is a challenge, finding information on sectoral variations in returns to schooling is more like a treasure hunt. After an extensive search, the only information that we could find is from Orazem (2006). Citing background work done for the World Bank's 2007 World Development Report, he notes that, for a sample of 41 developing countries, the average Mincerian return for each additional year of schooling in urban areas is $8.3 \%$ while for rural areas it is $7.5 \%$. In fact, most of the observed variation is not across sectors but across countries. ${ }^{12}$ On the basis of these findings, we assume that returns to education in agriculture are approximately $90 \%$ of the returns to education in 
the non-agricultural sector for all levels of education. We use HJ's numbers for the nonagricultural sector and then apply this adjustment to derive human capital returns in the agricultural sector for the three different levels of schooling. This, in conjunction with years of schooling, gives us human capital levels in the agricultural sector, $h_{a}$, and outside agriculture, $h_{n a}$. Equation (6) requires us to use the ratio $h_{n a} / h$. To ensure consistency, for the denominator, we calculated the implied average human capital in the economy, $h,^{13}$ as

$$
h=h_{a} \lambda_{a}+h_{n a}\left(1-\lambda_{a}\right),
$$

where $\lambda_{i}$, is the employment share in sector $i=a$, na. Therefore,

$$
\frac{h_{n a}}{h}=\frac{h_{n a}}{h_{a} \lambda_{a}+h_{n a}\left(1-\lambda_{a}\right)} .
$$

In the accounting exercises below, we incorporate these human capital and physical capital measures. At the same time, adding information on capital allocations reduces the size of the data-set considerably. In addition, the numbers are more contentious than the other variables. Hence we report variance decomposition both for the case without adjustments made for capital (the 'naive' version) and for the case where adjustments are made.

\section{(d) Results}

As a first exercise, we define

$$
C O M P 1 \equiv\left(\frac{Y / L}{Y_{n a} / L_{n a}}\right)
$$

and the residual as

$$
R E S 1=\frac{H J-T F P}{C O M P 1} \equiv\left(\frac{K_{n a} / Y_{n a}}{K / Y}\right)^{\alpha /(1-\alpha)}\left(\frac{h_{n a}}{h}\right) A_{n a} .
$$

In this case RESI (short for residual 1) will convey information about both relative and absolute efficiency. Below we refine the decomposition, pruning the residual for $\left(\left(K_{n a} / Y_{n a}\right) K / Y\right)^{\alpha /(1-\alpha)}$ and $\left(h_{n a} / h\right)$, thereby producing a more satisfactory split between relative and absolute efficiency. The cost associated with this added rigour is a smaller country coverage. Hence, to assess the implications of changing the sample, this first exercise is useful as a benchmark.

The variance decomposition itself uses the fact that

$$
\begin{aligned}
\operatorname{var}(\ln (H J-T F P))= & \operatorname{var}[\ln (C O M P 1)]+\operatorname{var}([\ln (R E S 1)]) \\
& +2 \operatorname{cov}([\ln (C O M P 1), \ln (R E S 1)]) .
\end{aligned}
$$

This equation highlights a problematic issue in any accounting analysis: the presence of a (non-zero) covariance term.

In standard accounting analyses, where the variance in $(\log )$ GDP per worker is decomposed into contributions from $K / Y, h$ and $T F P$, covariances between individual 'inputs' also have to be divided up. In theory, it is hard to interpret the covariances, as they almost certainly reflect bidirectional causal relationships. For example, a higher level of human capital may facilitate the adoption of technology (e.g. Nelson and Phelps 
TABLE 1

Summary STATISTiCs

\begin{tabular}{lccccr}
\hline Variance decomposition variables & $N$ & Mean & Std dev. & Min. & Max. \\
\hline $\begin{array}{l}H J-T F P \\
\text { (relative to USA) }\end{array}$ & 74 & 0.57 & 0.29 & 0.10 & 1.24 \\
$\begin{array}{l}C O M P 1 \\
\text { (relative to USA) }\end{array}$ & 74 & 0.62 & 0.30 & 0.09 & 1.05 \\
$\begin{array}{l}R E S 1 \\
\text { (relative to USA) }\end{array}$ & 74 & 1.01 & 0.51 & 0.35 & 3.73 \\
\hline
\end{tabular}

Note: The sample of 74 countries excludes countries in transition (formerly communist) and those with a mining sector greater than $15 \%$ of GDP.

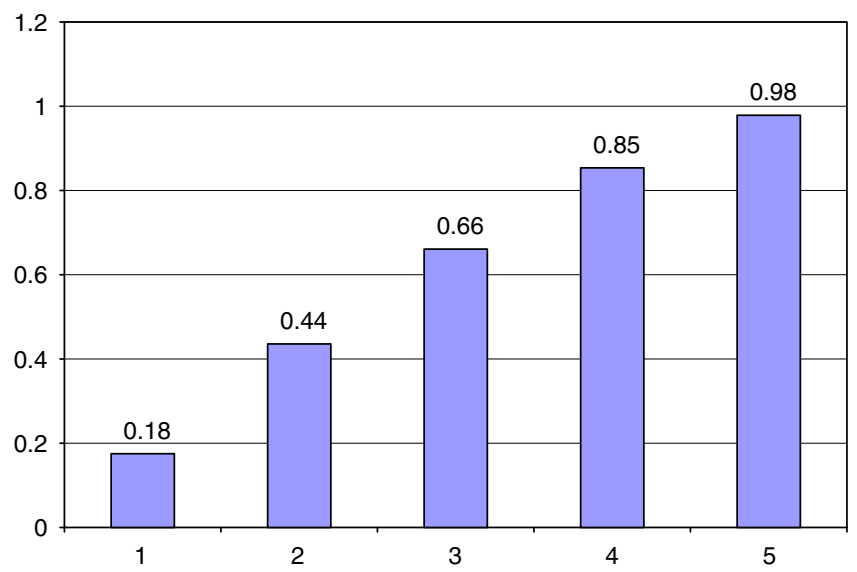

FIGURE 2. Relative worker productivity: economy-wide relative to non-agriculture (1985).

1966). If this were the only feasible interpretation of a correlation between $h$ and TFP, one could rightly attribute a positive covariance to human capital. However, it is also likely that technology affects the incentive to invest in schooling, thereby producing a causal link from technology to human capital (see Bils and Klenow 2000, for a discussion). As a result, it is unclear how to divide the covariance between $h$ and TFP. ${ }^{14}$

In the present context, nothing guarantees a priori that the covariance between COMP1 and RES1 is zero. If it is not, one needs to take a stance on how to assign it. Klenow and Rodriguez-Clare (1997) suggest splitting the covariance evenly, without strong beliefs about the direction of causality. Instead, we report it below so that the implications of dividing the covariance in different ways can be assessed.

Table 1 reports some summary statistics for $H J-T F P, C O M P 1$ and RES1. The variables are reported as relative to the United States. Of particular interest to us is the variation in COMPI-which, recall, is average labour productivity in the economy relative to labour productivity outside agriculture. Although the table lists the values relative to the United States, the numbers more or less reflect the absolute values too, since the value for United States itself is 0.99. Clearly, COMPI exhibits huge variations, ranging from 0.09 (Burkina Faso) to 1.04 (New Zealand). New Zealand is actually the only country that records a number higher than 1 (implying that its agricultural worker 
TABLE 2

CORRELATIONS

\begin{tabular}{lccc}
\hline Variance decomposition variables & HJ-TFP & COMP1 & RES1 \\
\hline HJ-TFP & 1 & - & - \\
COMP1 & 0.79 & 1 & - \\
RES1 & 0.22 & -0.41 & 1 \\
\hline
\end{tabular}

Note: For HJ-TFP, COMP and RES1 we used logged values in calculating correlations. This is meaningful since the variance decomposition exercise undertaken later also requires the use of logs. $N=74$.

productivity is higher than productivity in the rest of the economy). Most OECD countries have a relative productivity that is the upper end of the distribution, but less than 1. In Figure 2 we have divided the sample into quintiles to provide readers with a sense of the distribution of COMP1. Almost $40 \%$ of the sample has COMP1 values that are less than 0.5 . Since the numerator of COMP1 reflects overall labour productivity, this means that, in this group of countries agricultural labour productivity is less than $50 \%$ of non-agricultural productivity, owing to the former's much larger employment share. Indeed, it turns out that for almost half the sample of countries the agricultural sector productivity is less than $10 \%$ of non-agricultural productivity. The variation across countries in this dimension is astonishing.

Table 2 reports the correlations between the three variables. The highlight of this table, and an indicator of things to come, is the very strong correlation between COMPI and aggregate $T F P$ on the one hand and the relatively lower correlation between RESI and $T F P$ on the other.

The decomposition of TFP is undertaken by taking logs of the levels of HJ-TFP, $C O M P$ and $R E S$ and then using the fact that

$$
\begin{aligned}
1= & \frac{\operatorname{var}[\ln (C O M P 1)]}{\operatorname{var}[\ln (H J-T F P)]}+\frac{\operatorname{var}[\ln (R E S 1)]}{\operatorname{var}[\ln (H J-T F P)]} \\
& +2 \cdot \frac{\operatorname{cov}[\ln (C O M P 1), \ln (R E S 1)]}{\operatorname{var}[\ln (H J-T F P)]}
\end{aligned}
$$

Table 3, column (1) lists each of the terms in the above expression. As in Klenow and Rodriguez-Clare (1997), if we attribute half of the covariance to each of the two components, COMPI can easily account for about $85 \%$ of the variation in $T F P$ differences while RESI explains only $15 \%{ }^{15}$ The most conservative allocation of the covariances, from the dual economy perspective, would be to contribute all of the negative movements in the covariance to COMP1. Even then, the composition effect motivates as much as $56 \%$ of the total variation in aggregate $T F P$.

Results from variance decompositions can be sensitive to outliers, a point made by Caselli (2005). Therefore, to check for the sensitivity of the results we truncated the sample by $5 \%$ from each end of the distribution of COMP 1 ; that is, we removed the four lowest and the four highest observations of COMP1. Column (2) shows that this reduces the contribution from COMPI only marginally; COMP1 still explains almost $75 \%$ of the variation in aggregate $T F P$. As an additional sensitivity check, we dropped all OECD countries. Needless to say, this does reduce some of the variation observed in the data, but, as displayed in column (3), we find only a modest drop in the share that is accounted

(C) The London School of Economics and Political Science 2008 
TABLE 3

VARIANCE Decomposition

\begin{tabular}{lcccr}
\hline Shares & $(1)$ & $(2)$ & $(3)$ & $(4)$ \\
\hline $\operatorname{var}(C O M P 1)$ share & 1.14 & 0.91 & 1.15 & 0.47 \\
$\operatorname{var}($ RES1) share & 0.44 & 0.45 & 0.59 & 0.54 \\
$\operatorname{cov}($ COMP1, RES1) share & -0.29 & -0.18 & -0.37 & -0.01 \\
Implied share of COMP1 & 0.85 & 0.73 & 0.78 & 0.46 \\
Implied share of RES1 & 0.15 & 0.27 & 0.22 & 0.53 \\
$N$ & 74 & 66 & 52 & 22 \\
\hline
\end{tabular}

Note: Column (1) excludes all transition countries and those with mining shares greater than $15 \%$ of GDP. Column (2) additionally drops approximately $10 \%$ of the observations - 5\% of those with highest values of COMP1 and $5 \%$ of those with the lowest values ( 8 countries). Column (3) restricts the sample to non-OECD countries with mining shares less than $15 \%$ and not in transition ..., Column (4) uses only OECD countries with mining shares less than $15 \%$ and not in transition. 'Implied shares' are calculated by allocating the covariance equally to COMPI and RES1.

for by COMP1: to about $78 \%$. Finally, we limited the sample to just OECD countries. The variation now motivated by the composition term drops considerably, to $46 \%$. This is of course to be expected. These are all countries where the share of agriculture in GDP is small, and the relative productivity is consistently near 1. Overall, these results clearly suggest an important role for dual economy considerations in accounting for TFP differences.

Despite these encouraging results, one might still be concerned with the treatment of $\left(\left(K_{n a} / Y_{n a}\right) / K / Y\right)$ and $\left(h_{n a} / h\right)$. We tackle these issues next.

We first proceed to do a second decomposition, where $\left(\left(K_{n a} / Y_{n a}\right) /(K / Y)\right)^{\alpha /(1-\alpha)}$ is moved to the COMP term. We now have a more accurate measure of relative sector efficiency, which we label $C O M P 2$, and a correspondingly revised residual called RES2:

$$
R E S 2 \equiv \frac{H J-T F P}{\operatorname{COMPI}\left[\left(K_{n a} / Y_{n a}\right) /(K / Y)\right]^{\alpha /(1-\alpha)}} .
$$

These decomposition results are presented in Table 4. We are now limited to a much smaller number of countries, with the truncation taking place mainly at the lower end of the income distribution, thus also reducing the variation in the data. Out of the 46 countries for which we have data, 19 (or 40\%) are OECD countries. Despite that, the table suggests that the variance in $C O M P 2$ can explain around $60 \%$ of the variance in aggregate TFP. Columns (1)-(4) replicate the sample classification of Table 3. In Column (2) we again truncate the sample by about $10 \%$ (this time dropping countries with high and low values of COMP2); in column (3) we have only non-OECD countries, and in column (4) we have only OECD countries. As before, once we restrict the sample to OECD countries, the role of the composition effect is reduced although it remains sizeable.

When comparing Tables 3 and 4 it is clear that, once $\left[\left(K_{n a} / Y_{n a}\right) /(K / Y)\right]^{\alpha /(1-\alpha)}$ is taken into account, we are forced to reduce the underlying country coverage by almost half. How much of the change in results is simply due to this reduction? To check this, we conducted a decomposition in terms of COMP1 and RES1 (rather than COMP2 and $R E S 2)$ but for the smaller sample where data on $\left[\left(K_{n a} / Y_{n a}\right) /(K / Y)\right]^{\alpha /(1-\alpha)}$ are available. The results are reported in column (5), and they are virtually identical to those reported 
TABLE 4

Variance Decomposition (with Physical Capital)

\begin{tabular}{lccccc}
\hline Shares & $(1)$ & $(2)$ & $(3)$ & $(4)$ & $(5)$ \\
\hline $\operatorname{var}(C O M P 2)$ share & 0.60 & 0.53 & 0.58 & 0.51 & 0.64 \\
$\operatorname{var}($ RES2) share & 0.33 & 0.41 & 0.41 & 0.53 & 0.31 \\
$\operatorname{cov}($ COMP2, RES2) share & 0.03 & 0.03 & 0.01 & -0.02 & 0.02 \\
Implied share of COMP2 & 0.63 & 0.56 & 0.59 & 0.49 & 0.66 \\
Implied share of RES2 & 0.36 & 0.44 & 0.42 & 0.51 & 0.33 \\
$N$ & 46 & 42 & 27 & 19 & 46 \\
\hline
\end{tabular}

Notes: Column (1) excludes all transition countries and those with mining shares greater than $15 \%$ of GDP. Column (2) additionally removes 5\% each of the sample with the highest and lowest values of COMP2. Column (3) restricts the sample to non-OECD countries with mining shares less than $15 \%$ and not in transition. Column (4) uses only OECD countries with mining shares less than $15 \%$ and not in transition. Column (5) replaces COMP2 and RES2 with COMP1 and RES1. 'Implied shares' are calculated by allocating the covariance equally to $C O M P 2$ and $R E S 2$.

in column (1). Hence the reduction in the share accounted for by COMP is actually not produced by correcting for the allocation of capital; it is almost entirely driven by the reduction in the overall sample size, i.e. country selection. As a result, one is still in a position to conclude that relative efficiency is of substantial importance in accounting for aggregate TFP differences. Finally, note that in this reduced sample, while COMP2 accounts for two-thirds of the variation in aggregate $T F P$, the covariance term is almost zero. Thus, COMP2 and RES2 are more or less orthogonal to each other.

As a final exercise, we attempt to correct for human capital. The new composition term is labelled COMP3 and the corresponding residual, RES3, where COMP3 now fully captures our definition of $C O M P$ given by equation (6) repeated below for convenience,

$$
\text { COMP3 }=\left\{\frac{\left[\left(K_{n a} / Y_{n a}\right) /(K / Y)\right]^{\alpha /(1-\alpha)}\left(h_{n a} / h\right)}{\left(Y_{n a} / L_{n a}\right) /(Y / L)}\right\},
$$

and RES3 is,

$$
R E S 3 \equiv \frac{H J-T F P}{C O M P 3} .
$$

Table 5 lists the results of this new decomposition. Note that the sample size falls further. Compared with Table 3, the role of relative efficiency is now diminished, although the contribution from COMP3 still exceeds $50 \%$ in the largest possible sample. This result remains more or less the same irrespective of whether we drop all OECD countries (column (3)) or focus only on OECD countries (column (4)). Removing the outlier countries (column (2)) reduces the implied share of composition effects to $42 \%$. Finally, in column (5) we perform a decomposition exercise, using COMP1, on the same sample as is available for $C O M P 3$ (cf. column (1)). In comparison, it is clear that adding human capital lowers the contribution of COMP and the weakened results are not being driven just by sample selection.

The reason for the weakened results is simply that COMP2 and $h_{n a} / h$ are negatively correlated (recall COMP3 $\left.=C O M P 2 \times h_{n a} / h\right)$. Countries where the relative level of human capital outside agriculture is high will also tend to have high levels of relative labour productivity outside the agricultural sector. Since the latter enters the 
TABLE 5

Variance Decomposition (with Physical and Human Capital)

\begin{tabular}{lccccc}
\hline Shares & $(1)$ & $(2)$ & $(3)$ & $(4)$ & $(5)$ \\
\hline $\operatorname{var}(C O M P 3)$ share & 0.48 & 0.38 & 0.445 & 0.462 & 0.60 \\
$\operatorname{var}($ RES3) share & 0.39 & 0.54 & 0.49 & 0.529 & 0.35 \\
cov(COMP3, RES3) share & 0.065 & 0.04 & 0.032 & 0.004 & 0.025 \\
Implied share of COMP3 & 0.545 & 0.42 & 0.477 & 0.466 & 0.625 \\
Implied share of RES3 & 0.455 & 0.58 & 0.522 & 0.533 & 0.375 \\
$N$ & 40 & 38 & 23 & 17 & 40 \\
\hline
\end{tabular}

Notes: Column (1) excludes all transition countries and those with mining shares greater than $15 \%$ of GDP. Column (2) additionally removes $5 \%$ of the sample with the highest and lowest values of COMP3. Column (3) restricts the sample to non-OECD countries with mining shares less than $15 \%$ and not in transition. Column (4) uses only OECD countries with mining shares less than $15 \%$ and not in transition. Column (5) uses COMP1 and RES1 instead of COMP3 and RES3. 'Implied shares' are calculated by allocating the covariance equally to COMP3 and RES3.

denominator of COMP2, one would expect $h_{n a} / h$ and COMP2 to be negatively correlated. In fact, the correlation between $h_{n a} / h$ and COMP2 is -0.89 (for the 40 countries in Table 5). As a result, the variation in COMP3 will be considerably lower than the variation in $C O M P 2$, and thus, the former will have a more limited role in accounting for aggregate TFP differences. Nevertheless, even with a diminished contribution, one can conclude that the relative efficiency effect still accounts for roughly $50 \%$ of the variation in aggregate total factor productivity. Also noteworthy is the low covariance between COMP3 and RES3, as reported in Table 5, indicating that the contribution from COMP3 is fairly well determined.

The overall conclusion from the decompositions is that the dual economy perspective seems to be of first-order importance. In a broad sample of countries, the contribution of relative efficiency in accounting for aggregate $T F P$ is at the very least $50 \%$ and possibly as high as $85 \%$. This finding naturally fuels an interest in trying to discern what fundamental economic variables might be driving the composition term in the first place. In the next section we examine this question.

\section{REGRESSION ANALYSIS}

\section{(a) Specification}

Employing cross-country regression analysis over the last handful of years, a number of contributions have attempted to come to grips with what fundamentally determines why some countries are more productive than others. While it is still too early to speak of a consensus on this topic, three competing hypotheses stand out.

The first hypothesis, building upon the work by North (1990), Engerman and Sokoloff (1997, 2000), among others, and empirically supported by Hall and Jones (1999), Acemoglu et al. (2001, 2002) and Easterly and Levine (2003), is that property rights institutions are important. That is, the underlying structures that form the legal and political rules of the game for activities within society are central to aggregate productivity. Indeed, with better established property rights and a well functioning state - in short, 'strong institutions' - one would expect to find agents faced with incentives for productive effort rather than socially costly rent-seeking activities or 
predation. ${ }^{16}$ In our analysis, we initially employ a broad based measure of institutional quality which captures both aspects of economic and political institutions, as explained below. However, we also examine more specific dimensions of institutional quality: property rights, contracting institutions and financial development. The second hypothesis, associated with the work of Frankel and Romer (1999) and Alcalá and Ciccone (2004), shows that outward orientation - openness to trade and interaction with other nations - is an important element behind successful development trajectories. Finally, the work of Diamond (1997), Gallup et al. (1999) and Hibbs and Olsson (2005), among others, suggests that geographic circumstances are key. ${ }^{17}$

In the present context, we implement a parsimonious specification which nests the aforementioned three, but by no means mutually exclusive, hypotheses. ${ }^{18}$ Our goal is to examine the extent to which some, or all, of these fundamental sources of prosperity affect TFP because they ultimately influence relative efficiency between sectors, as captured by the composition term derived above, or because they determine the size of the left-over residual, which can be interpreted as the level of TFP outside agriculture.

Accordingly, in this section we estimate an equation of the following form:

$$
\log X_{i}=\beta_{0}+\beta_{1} I N S T I T U T I O N S_{i}+\beta_{2} \text { OPENNESS }_{i}+\beta_{3} \text { GEOGRAPHY }_{i}+e_{i},
$$

where $X$ is either TFP or one of its two sub-components, i.e. the composition term or the remaning residual, whereas $e_{i}$ is a disturbance term which captures noise and omitted variables. More specifically, we examine the influence of institutions, openness and geography on both the naive composition term, COMP1, and the version where we take capital into account, COMP2. ${ }^{19}$ The dependent variables - the level of aggregate TFP, $C O M P 1, C O M P 2, R E S 1$ and $R E S 2$ - are described above and, as explained, pertain to 1985. It is clear that COMP2 in some sense is a more satisfactory measure of relative efficiency since we take the allocation of physical capital into account. However, invoking this measure limits our sample severely. For this reason we report the results from using both decompositions as left-hand-side variables. We do not perform regressions involving $C O M P 3$, since the ultimate sample under consideration becomes miniscule.

Previous research has focused on establishing a link between INSTITUTIONS, $O P E N N E S S$ and GEOGRAPHY on the one hand, and the level of efficiency on the other. However, one may wonder why they should be related to relative efficiency across sectors (i.e. $C O M P$ ). As far as we are aware, this is the first paper to relate the literature on 'deep determinants' to dual economy aspects of development. Thus, there is no established theory to fall back on. Nevertheless, we can suggest plausible links.

A strong association between institutions and relative efficiency could be motivated by theories like those of Restuccia (2004) and Landon-Lane and Robertson (2005). In these models 'barriers' to capital accumulation or frictions in labour mobility affects structural change and thereby aggregate productivity. To the extent that such frictions are the result of weak contracting institutions or poorly protected property rights, one would expect a link between these aspects of an economy's institutional infrastructure and relative sectoral efficiency. In similar vein, we expect a potentially important effect from financial development to relative efficiency. After all, the central role of a well functioning financial sector is to ensure an efficient allocation of scarce resources (Beck et al. 2003); hence, a lack of financial development should imply lower levels for COMP.

In addition to the institutional variables, we also include international trade. As mentioned above, openness to trade has been shown to have a significant exogenous impact on differences in average worker productivities, though it remains a debated issue

(C) The London School of Economics and Political Science 2008 
(e.g. Rodrik et al. 2004). Its effect on aggregate TFP differences has also been the subject of a rich literature going back to Coe and Helpman (1995). Most of this literature is based on the assumption that TFP differences largely reflect technology differences and that international trade accelerates the diffusion of technologies. In terms of our decomposition, the natural corollary would be that absolute efficiency should be a positive function of openness to international trade. However, for our decomposition things might be more blurred. Since non-agricultural TFP is not necessarily the same as manufacturing TFP, the correlation will be weakened because of the presence of the nontradable service sector (which is on the rise in both developed and developing countries). Moreover, even if RES captured TFP in manufacturing, trade may not necessarily increase productivity: international trade may intensify competition, which in theory could have an ambiguous effect on the incentive to innovate (e.g. Aghion and Griffith 2005). In terms of the impact of trade on relative efficiency, we also note that this association may be ambiguous. On the one hand, trade may lead to specialization, which is associated with static efficiency gains. This effect should work so as to increase COMP. However, the theoretical work of Matsuyama (1992) and Galor and Mountford (2006) suggests that opening to trade may lower overall productivity in some cases, by causing specialization in the 'wrong' sector.

Our third and final set of variables pertains to geography. There is a long tradition of geography-based hypotheses that aims to explain differences in per capita incomes. Here we discuss a few of the dominant ones. The 'temperate drift' hypothesis argues that the modernization of agriculture involved the introduction of new crops such as wheat and barley, domestication of animals and better technologies such as crop-rotation. According to this hypothesis, all of these were more conducive for countries in temperate zones than in tropical areas. If true, this hypothesis would certainly reflect itself in lower agricultural productivity in the tropics. An alternative hypothesis argues that, with the onset of industrialization, access to oceans and navigable waterways became important because of the associated role of trade. Finally, there is of course the more straightforward geography hypothesis, i.e. that the disease environment in the tropics makes workers more unproductive and this keeps economies in low-level poverty traps characterized by large unproductive agricultural sectors. ${ }^{20}$

In the following subsection we estimate the above equation by ordinary least squares (OLS). However, since INSTITUTIONS and OPENNESS are inherently endogenous, this approach is unlikely to convey accurate information about causal relationsships. Consequently, we also estimate the model by way of two-stage least squares (2SLS). The latter requires us to provide adequate instruments for INSTITUTIONS and OPEN$N E S S$, as explained below.

\section{(b) Measuring institutions, openness and geography}

In measuring institutions we initially rely on the Government Anti-Diversionary Policy index $(G A D P)$. This variable was used by Hall and Jones (1999), which is our data source. This index, introduced into the literature by Knack and Keefer (1995) and created by Political Risk Services, is an average of five indices capturing the quality of government: rule of law, bureaucratic quality, risk of expropriation by the government, government repudiation of contracts, and corruption. An advantage of this measure is its broad country coverage, and in fact that we can reuse the instruments suggested by Hall and Jones for the purpose of identification. In addition, since Hall and Jones used this measure to explain differences in $T F P$, it is of obvious interest to see whether this variable

(C) The London School of Economics and Political Science 2008 
plays a role in explaining our two sub-components of TFP. However, the GADP index also has a drawback, in being a somewhat imprecise measure of institutions; it simultaneously captures a number of institutional aspects (although they are all highly correlated with each other). We therefore also employ a set of less diffuse measures of institutional quality.

The number of variables capturing different aspects of institutional quality has proliferated over the past few years in tandem with the rising interest in explaining development via institutions. Since it is impossible to focus on all the variables, we limit ourselves to a few that are examined in Acemoglu and Johnson (2005). In particular, these others attempt to distinguish between 'property rights' institutions and 'contracting' institutions. ${ }^{21}$ In addition, they examine the role of financial development, which has been argued to have a significant effect on productivity (see e.g. Levine 2005). In order to capture the protection of property rights (henceforth, PROPERTY) we rely on the 'risk of expropriation' index, which comes from Political Risk Services and is the average for the period 1982-85. ${ }^{22}$ This index has also been employed in Acemoglu et al. (2001). To measure the quality of contracting institutions, we follow Acemoglu and Johnson (2005) and use an index for legal complexity (CONTRACT), compiled by Djankov et al. (2003). ${ }^{23}$ The basic idea is that greater legal complexity introduces transaction costs, making it harder to enforce contracts. Their index looks at legal complexity involved in resolving relatively simple disputes such as a bounced cheque or eviction of defaulting residential tenants. Finally, following Beck et al. (2003), we measure financial market development by private credit as a fraction of GDP (FINANCE). This variable is averaged over the 1980-1985 period and is obtained from Beck et al. (2000). ${ }^{24}$

Trade is measured as (the logarithm of) the sum of nominal imports, and exports as a fraction of nominal GDP $(T R A D E) .{ }^{25}$ In a recent contribution, Alcalá and Ciccone (2004) espouse an alternative measure, REAL TRADE, which is derived as the ratio of nominal imports and exports as a fraction of PPP GDP. We also experimented with using this variable instead of TRADE; however, since results are very similar, the reported results include only specifications involving TRADE. TRADE and REAL $T R A D E$ were calculated for 1985, and the source is World Development Indicators 2005 CD-ROM (World Bank 2006).

To capture geographic determinants, we use continent dummies (America, Asia, Europe and Africa; the latter is omitted here), as well as two other geo-controls that have proved to be strong determinants of living standards: a dummy variable that takes on the value of 1 if a country is landlocked ( $L A N D L O C K)$, and a variable that measures the fraction of country situated in the geographical tropics (TROPICS). The source of both these variables is Gallup et al. (1999).

Tables 6 and 7 provide summary statistics for key variables and their mutual (simple) correlations in the context of our maximum sample, which involves COMP1 and the $G A D P$ institutional measure. For brevity, we have omitted the three specific measures of institutions (PROPERTY, CONTRACT and FINANCE) from the correlation matrix. Nothing much is lost, however, since these three measures are highly correlated with $G A D P$, at $0.92,-0.47$ and 0.65 , respectively. ${ }^{26}$

A noteworthy feature of the correlation matrix is the relatively high positive correlation between COMP1, REAL TRADE, TRADE and GADP. ${ }^{27}$ In contrast, the correlation between our measure of institutions and the residual is, in fact, negative. The same goes for the association between RES1 and the trade variables. Notice also that REAL TRADE is far more correlated with TFP than TRADE is. Nevertheless, we get similar qualitiative regression results. Moreover, a problem that arises when using $R E A L$

(C) The London School of Economics and Political Science 2008 
TABLE 6

Summary STATISTICS

\begin{tabular}{lccccr}
\hline Regression Variables & OBS & Mean & St. Dev. & Min. & Max. \\
\hline $\log ($ TFP $)$ & 76 & 8.06 & 0.60 & 6.51 & 9.01 \\
$\log ($ COMP 1$)$ & 76 & -0.64 & 0.65 & -2.38 & 0.05 \\
$\log ($ RES $)$ & 76 & 8.70 & 0.41 & 7.76 & 10.12 \\
GADP & 76 & 0.63 & 0.21 & 0.23 & 1 \\
TRADE & 76 & 3.82 & 0.48 & 2.58 & 4.79 \\
REAL TRADE & 76 & 3.05 & 0.65 & 1.40 & 4.41 \\
TROPICS & 76 & 0.19 & 0.25 & 0 & 0.99 \\
LANDLOCK & 76 & - & - & 0 & 1 \\
PROPERTY & 73 & 6.07 & 2.11 & 1.63 & 9.87 \\
CONTRACT & 60 & 3.78 & 0.99 & 1.41 & 5.91 \\
FINANCE & 71 & 0.40 & 0.32 & 0.02 & 1.46 \\
\hline
\end{tabular}

TABLE 7

Correlation Matrix (REgression VAriables)

\begin{tabular}{|c|c|c|c|c|c|c|c|c|}
\hline & $\begin{array}{c}\log \\
(T F P)\end{array}$ & $\begin{array}{c}\log \\
(C O M P 1)\end{array}$ & $\begin{array}{c}\log \\
(R E S 1)\end{array}$ & $G A D P^{\prime}$ & $T R A D E$ & $\begin{array}{c}\text { REAL } \\
\text { TRADE }\end{array}$ & TROPI & $\mathrm{VDLOCK}$ \\
\hline $\log (T F P)$ & 1 & 一 & - & - & 一 & 一 & - & - \\
\hline $\log (C O M P 1)$ & 0.78 & 1 & - & - & - & - & - & - \\
\hline $\log (R E S 1)$ & 0.23 & -0.43 & 1 & - & - & - & - & - \\
\hline$G A D P$ & 0.57 & 0.60 & -0.12 & 1 & 一 & 一 & 一 & - \\
\hline$T R A D E$ & 0.06 & 0.18 & -0.21 & 0.31 & 1 & 一 & - & - \\
\hline $\begin{array}{l}\text { REAL } \\
\quad \text { TRADE }\end{array}$ & 0.38 & 0.37 & -0.03 & 0.64 & 0.76 & 1 & - & - \\
\hline TROPICS & -0.50 & -0.40 & -0.10 & -0.38 & -0.13 & -0.28 & 1 & - \\
\hline$L A N D L O C K$ & -0.44 & -0.54 & 0.21 & -0.19 & 0.02 & -0.10 & 0.03 & 1 \\
\hline
\end{tabular}

Notes: $\log (T F P)$ is the $\log$ of aggregate total factor productivity for 1985 ; $\log (C O M P)$ is the 'naïve' composition effect, neglecting capital allocation; log $(R E S)$ equals $\log (T F P)-\log (C O M P)$; GADP is the government anti-diversion policy index, taken from Hall and Jones (1999). TRADE is to the (log of the) ratio of nominal imports + exports as a fraction of nominal GDP; it is calculated for 1985, and the underlying source is the World Development Indicators CD-ROM 2005. REAL TRADE is defined as (the log of) nominal imports + exports as a fraction of PPP GDP and is also calculated for 1985; TROPICS is the fraction of the land area situated in the geographical tropics, and $L A N D L O C K$ is a dummy variable which takes the value 1 if a country is landlocked. (Both variables are from Gallup et al. 1999.) PROPERTY measures the risk of expropriation, averaged over 1982-85; CONTRACT measures legal formalism, and is taken from Djankov et al. (2003); FINANCE is bank credit as a fraction of GDP as an average for the 1980-85 period, source: is Beck et al. (2000). $N=76$.

$T R A D E$ as an independent variable is that our instruments often turn out to be weak. A potential explanation lies in the high correlation between REAL TRADE and GADP, as seen from the table. This high correlation makes the task of separately identifying the impact from international interaction and institutions harder. In contrast, we may notice that the correlation between $T R A D E$ and $G A D P$ is only half as strong. Finally, the strength of the correlation between the two geographical variables and COMP1 is also quite strong. In particular, the negative correlation between being landlocked and COMP1 is -0.54 and that of tropics and COMP1 is -0.41 . On the other hand, their 
correlations with RES1 are much weaker and in opposite directions. In particular, being landlocked is positively correlated with non-agricultural TFP, thus placing in doubt the landlock-industrialization relationship discussed earlier. ${ }^{28}$

\section{(c) Choice of instruments}

When we estimate the model with maximum sample size, which involves the GADP measure, we rely on two sets of instruments. The first set comprises of essentially those adopted by Hall and Jones (1999): (i) the fraction of the population speaking a European language, (ii) the (absolute) latitude of a country, and (iii) fitted trade shares deriving from the estimation of a gravity equation. ${ }^{29}$ The first two variables are thought to capture 'distance' to, or penetration of, European institutions which supposedly proved their worth in facilitating the Industrial Revolution. Countries close to Europe, physically and metaphorically, are likely to have implemented similar institutions, perhaps greatly influenced by colonial rule, which should make both distance measures potential determinants of GADP. The third variable is included to instrument TRADE. Whereas Hall and Jones (1999) used fitted trade shares from the study by Frankel and Romer (1999), we employ the updated and improved version developed by Alcalá and Ciccone (2004).

The second set of instruments comprises: (i) settler mortality rates in the late nineteenth century, introduced by Acemoglu et al. (2001), (ii) the (log) population size, and (iii) $(\log )$ land area in $\mathrm{km}^{2}$. Both population size and land area are taken from the WDI. The settler mortality rates are used as an instrument for GADP, based on the theory developed by Acemoglu et al. (2001). ${ }^{30}$ The two remaining instrumentspopulation size and land area-are motivated by their likely impact on TRADE. As is well known, the trade of large countries tends to be less when measured as a fraction of total economic activity (e.g. Rose 2006). Indeed, in the gravity equation that underlies the fitted trade shares, mentioned above, population size and area are included as RHS variables. Consequently it is not surprising that the pure correlation between the fitted trades share and the two measures of country size is high, at -0.75 (population) and -0.6 (land areas). We therefore use these measures of country size directly as alternative instruments for TRADE.

In the part of the analysis where we use more specific measures of institutions, we generally stick with the second set of instruments. That is, TRADE continues to motivate $\log$ (area) and $\log$ (population), whereas settler mortality rates is included in the set of instruments to instrument for PROPERTY and FINANCE. Whereas Acemoglu et al. (2001) develop a theory that links settler mortality rates explicitly to PROPERTY, Beck et al. (2003) develop an argument in favour of using the mortality data to explain currentday financial development. ${ }^{31}$ The only exception to this procedure arises when we examine the impact of CONTRACT on TFP, COMP and RES. In this batch of regressions we substitute the settler mortality rates for a French legal origin dummy, following Djankov et al. (2003) and Acemoglu and Johnson (2005).

Each of the two sets of instruments have their own strengths and weaknesses. The advantage of the first set is greater country coverage. When we employ this set, along with $G A D P$ as a measure for institutions, we can examine the determinants of COMP1 (COMP2) and RES1 (RES2) for 74 (46) countries. The drawback is that the theory underlying the use of the language variable and absolute latitude as instruments for institutions is not overly convincing. On the latter score, the instrument suggested by Acemoglu et al. (2001) is arguably superior. However, employing this instrument limits our sample considerably, bringing the country coverage down to 50 (COMPI) and

(C) The London School of Economics and Political Science 2008 
a mere $25(C O M P 2)$, respectively. We see little point in examining the 25 country sample by 2 SLS. Hence, when we use the second set of instruments, attention is confined to COMPI and RESI regressions; likewise, when we examine the impact from PROPERTY, CONTRACT and FINANCE attention will be confined to regressions involving TFP, COMPI and RESI.

\section{(d) Results}

Tables 8 and 9 document the partial (OLS) correlations between TFP, COMPI, $C O M P 2, R E S 1$ and RES2 on the one hand, and our baseline choice of explanatory

TABLE 8

OLS REGRESSIONS

\begin{tabular}{|c|c|c|c|c|c|c|}
\hline & $\log (T F P)$ & $\log (T F P)$ & $\log (C O M P 1)$ & $\log (C O M P 1)$ & $\log (R E S 1)$ & $\log (R E S 1)$ \\
\hline & 1 & 2 & 3 & 4 & 5 & 6 \\
\hline$G A D P$ & $\begin{array}{l}1.73^{* * * * *} \\
(8.64)\end{array}$ & $\begin{array}{l}0.88^{* * * * *} \\
(3.10)\end{array}$ & $\begin{array}{l}1.85^{* * * * *} \\
(8.34)\end{array}$ & $\begin{array}{l}1.15^{* * * * *} \\
(5.10)\end{array}$ & $\begin{array}{c}-0.12 \\
(0.51)\end{array}$ & $\begin{array}{r}-0.28 \\
(0.82)\end{array}$ \\
\hline$T R A D E$ & $\begin{array}{r}-0.17 \\
(1.32)\end{array}$ & $\begin{array}{c}-0.12 \\
(1.18)\end{array}$ & $\begin{array}{r}-0.01 \\
(0.04)\end{array}$ & $\begin{array}{c}0.11 \\
(1.05)\end{array}$ & $\begin{array}{r}-0.16 \\
(1.57)\end{array}$ & $\begin{array}{c}-0.23^{\text {*** }} \\
(2.27)\end{array}$ \\
\hline TROPICS & & $\begin{array}{c}-0.71^{* * * *} \\
(3.47)\end{array}$ & & $\begin{array}{r}-0.41^{*} \\
(1.89)\end{array}$ & & $\begin{array}{c}-0.31 \\
(1.35)\end{array}$ \\
\hline LANDLOCKED & & $\begin{array}{c}-0.48^{* * * *} \\
(3.28)\end{array}$ & & $\begin{array}{c}-0.61^{* * * * *} \\
(3.88)\end{array}$ & & $\begin{array}{r}-0.13 \\
(0.96)\end{array}$ \\
\hline CONTINENTS & No & Yes & No & Yes & No & Yes \\
\hline$R^{2}$ & 0.33 & 0.60 & 0.36 & 0.74 & 0.05 & 0.20 \\
\hline$N$ & 76 & 76 & 76 & 76 & 76 & 76 \\
\hline
\end{tabular}

Notes: All regressions contain a constant.

$*, * *, * * * *$ Indicate significance at $10 \%, 5 \%$ and $1 \%$, respectively. Absolute $t$-values in parentheses; based on robust standard errors.

TABLE 9

OLS Regressions: Alternative Decomposition

\begin{tabular}{|c|c|c|c|c|c|c|}
\hline & $\log (T F P)$ & $\log (T F P)$ & $\log (C O M P 2)$ & $\log (C O M P 2)$ & $\log (R E S 2)$ & $\log (R E S 2)$ \\
\hline$G A D P$ & $\begin{array}{l}1.38^{* * * *} \\
(4.59)\end{array}$ & $\begin{array}{l}0.73^{* * * *} \\
(2.17)\end{array}$ & $\begin{array}{l}1.25^{\text {***** }} \\
(6.10)\end{array}$ & $\begin{array}{l}0.99^{* * * * *} \\
(4.81)\end{array}$ & $\begin{array}{c}0.08 \\
(0.37)\end{array}$ & $\begin{array}{r}-0.28 \\
(0.78)\end{array}$ \\
\hline$T R A D E$ & $\begin{array}{r}-0.10 \\
(0.61)\end{array}$ & $\begin{array}{r}-0.09 \\
(0.67)\end{array}$ & $\begin{array}{c}0.02 \\
(0.23)\end{array}$ & $\begin{array}{c}0.13^{*} \\
(1.80)\end{array}$ & $\begin{array}{c}-0.12 \\
(1.23)\end{array}$ & $\begin{array}{c}-0.21^{* * *} \\
(2.13)\end{array}$ \\
\hline TROPICS & & $\begin{array}{r}-0.91^{*} \\
(1.93)\end{array}$ & & $\begin{array}{r}-0.48^{*} \\
(1.92)\end{array}$ & & $\begin{array}{r}-0.42 \\
(1.36)\end{array}$ \\
\hline LANDLOCKED & & $\begin{array}{c}-0.55 \\
(1.44)\end{array}$ & & $\begin{array}{c}-0.41 \\
(1.68)\end{array}$ & & $\begin{array}{r}-0.14 \\
(0.96)\end{array}$ \\
\hline CONTINENTS & No & Yes & No & Yes & No & Yes \\
\hline$R^{2}$ & 0.28 & 0.50 & 0.40 & 0.74 & 0.03 & 0.19 \\
\hline$N$ & 46 & 46 & 46 & 46 & 46 & 46 \\
\hline
\end{tabular}

Notes: All regressions contain a constant.

$*, * *, * * *$ Indicate significance at $10 \%, 5 \%$ and $1 \%$, respectively. Absolute $t$-values in parentheses; based on robust standard errors.

(C) The London School of Economics and Political Science 2008 
variables on the other. We report two specifications: one without any geo-controls, and one with the full set of geo-controls, as described above. ${ }^{32}$

As seen, GADP is strongly related to both $T F P$ and the two COMP terms. It is, however, not significantly correlated with the left-over residual, regardless of specification. TRADE is insignificant in all specifications. Finally, geographic circumstances are strongly related to TFP and COMP1, but not to RES1. Furthermore, the introduction of the geographical variables reduces the impact of GADP considerably. In fact, the coefficient falls in value by approximately half. Also note that, when adding geographical variables (going from column (1) to (2), or (3) to (4)), the fraction of the variation that is explained also doubles. Thus, geographical explanations seem to be at least as important as institutional explanations. The results from the smaller sample (Table 9) are less strong in this respect, but generally lean in the same direction. While we cannot discern causal relationships from OLS regressions, they do suggest a strong association between GADP, GEOGRAPHY and the measures that reflect the relative sectoral efficiency.

In Table 10 we provide IV estimates of the impact from institutions and trade on TFP, COMP and RES. The instruments are those suggested in Hall and Jones (1999), and Table 10(a) reports the first stage. As is clear, the fitted trade shares are highly significant in explaining measured trade, whereas they hold no explanatory power for the $G A D P$ index. Conversely, latitude and the fraction of the population speaking a European language are significant determinants of GADP, but not of TRADE. This holds with or without our set of geo-controls. Moreover, the geo-controls themselves seem to not have any explanatory power for either GADP or TRADE, and adding them raises the $R^{2}$ only by 0.08 for $G A D P$ and not at all for $T R A D E$.

Table 10(b) reports the results from estimating the regression model using 2SLS. A simple examination suggests that institutions continue to be significant in explaining TFP and COMPI. If anything, the size of the coefficient seems to increase relative to the OLS estimates. To get a sense of the quantitative impact of GADP, consider the effect of a one standard-deviation increase in GADP (0.21) on COMP1. From column (4), the effect on $C O M P 1$ is $1.81 \times 0.21=0.38$, which is a little more than half a standard deviation increase in $C O M P 1$. For a more concrete example, consider a country at around the mean value of COMP1 (-0.64). Examples of such countries are Guatemala and Sri Lanka. A one-standard-deviation increase in GADP would make the COMPl value of these countries comparable to the lower end of high-income countries such as Korea, Greece or Portugal. This is clearly a significant quantitative effect. With regards to the geo-controls, we find that TROPICS is no longer significantly associated with any of the three dependent variables. However, LANDLOCK continues to wield a significant negative effect on both aggregate TFP and relative sectoral efficiency (with the size of the coefficient being similar to that in the OLS estimates). When it comes to estimation of instrumental variables, one needs to be careful not to get carried away with significance, and a number of tests need to be conducted to satisfy ourselves regarding validity, weakness, etc.

The first important test concerns the validity of the instruments, i.e. the restriction that the three instruments can be omitted from the second stage. Based on the Hansen $J$-statistic, we are unable to reject the over-identifying restrictions when we condition fully for geography. Even if valid, however, instruments may be weak, which makes inference based on 2SLS unreliable (Stock et al. 2002). ${ }^{33}$ The standard approach to assessing instrument weakness is the rule-of-thumb derived in Staiger and Stock (1997) and concerns regressions involving one endogenous variable. The rule-of-thumb states

(C) The London School of Economics and Political Science 2008 
TABLE 10(a)

First Stage Regressions

\begin{tabular}{lcccc}
\hline & GADP & TRADE & GADP & TRADE \\
\hline EURFRAC & $0.10^{* * *}$ & 0.09 & $0.17^{* * * *}$ & 0.17 \\
& $(2.49)$ & $(0.72)$ & $(3.44)$ & $(1.00)$ \\
ABSLAT & $0.80^{* * * *}$ & 0.00 & $0.65^{* * * *}$ & 0.14 \\
& $(8.67)$ & $(0.02)$ & $(4.94)$ & $(0.32)$ \\
FITTED TRADE & -0.00 & $0.46^{* * * *}$ & -0.04 & $0.49^{* * * *}$ \\
& $(0.05)$ & $(5.29)$ & $(1.57)$ & $(4.78)$ \\
TROPICS & & & 0.1 & 0.12 \\
& & & $(1.38)$ & $(0.49)$ \\
LANDLOCK & & & -0.03 & 0.23 \\
& $\mathrm{No}$ & $\mathrm{No}$ & $(0.59)$ & $(1.55)$ \\
CONTINENTS & 0.60 & 0.31 & Yes & Yes \\
Adj. R $^{2}$ & 74 & 74 & 0.68 & 0.30 \\
$N$ & & & 74 & 74 \\
\hline
\end{tabular}

Notes: All regressions contain a constant.

$*, * *, * * *$ Indicate significance at $10 \%, 5 \%$ and $1 \%$, respectively. Absolute $t$-values in parenthesis; based on robust standard errors.

TABLE 10(b)

2SLS REGRESSIONS

\begin{tabular}{|c|c|c|c|c|c|c|}
\hline & \multicolumn{6}{|c|}{$\log (T F P) \log (T F P) \log (C O M P 1) \log (C O M P 1) \log ($ RES1) $\log ($ RES 1$)$} \\
\hline & (1) & (2) & (3) & (4) & (5) & (6) \\
\hline$G A D P$ & $\begin{array}{l}2.49^{* * * *} \\
(7.10)\end{array}$ & $\begin{array}{l}1.87^{* * * *} \\
(3.22)\end{array}$ & $\begin{array}{l}2.62^{* * * * *} \\
(6.51)\end{array}$ & $\begin{array}{l}1.81^{* * * * *} \\
(3.23)\end{array}$ & $\begin{array}{r}-0.13 \\
(0.41)\end{array}$ & $\begin{array}{c}0.06 \\
(0.12)\end{array}$ \\
\hline$T R A D E$ & $\begin{array}{c}0.21 \\
(0.95)\end{array}$ & $\begin{array}{c}0.34 \\
(1.53)\end{array}$ & $\begin{array}{c}0.12 \\
(0.61)\end{array}$ & $\begin{array}{c}0.22 \\
(1.43)\end{array}$ & $\begin{array}{c}0.09 \\
(0.57)\end{array}$ & $\begin{array}{c}0.12 \\
(0.59)\end{array}$ \\
\hline TROPICS & & $\begin{array}{l}-0.58^{* * * *} \\
(2.67)\end{array}$ & & $\begin{array}{r}-0.32 \\
(1.41)\end{array}$ & & $\begin{array}{r}-0.26 \\
(1.21)\end{array}$ \\
\hline$L A N D L O C K E D$ & & $\begin{array}{l}-0.41^{* * * *} \\
(2.94)\end{array}$ & & $\begin{array}{l}-0.58^{* * * *} \\
(3.88)\end{array}$ & & $\begin{array}{c}0.17 \\
(1.24)\end{array}$ \\
\hline CONTINENTS & No & Yes & No & Yes & No & Yes \\
\hline Hansen $J$ statistic ( $p$-value) & 0.06 & 0.77 & 0.00 & 0.88 & 0.05 & 0.86 \\
\hline Cragg-Donald statistic & 10.83 & 5.12 & 10.83 & 5.12 & 10.83 & 5.12 \\
\hline Pagan-Hall ( $p$-value) & 0.41 & 0.59 & 0.01 & 0.21 & 0.07 & 0.53 \\
\hline $\begin{array}{l}\text { Anderson-Rubin statistic } \\
\text { ( } p \text {-value })\end{array}$ & 0.000 & 0.003 & 0.000 & 0.007 & 0.23 & 0.94 \\
\hline$N$ & 74 & 74 & 74 & 74 & 74 & 74 \\
\hline
\end{tabular}

Notes: All regressions contain a constant.

$*, * *, * * *$ Indicate significance at $10 \%, 5 \%$ and $1 \%$ respectively. Absolute $t$-values in parentheses; based on robust standard errors.

Excluded instruments: Eurfrac, Absolute latitude and fitted trade shares, as explained in the text.

The Hansen $J$ statistic tests whether the exclusion restriction is valid; the null is that the instruments can be excluded from the second stage. The Cragg-Donald statistic, for which the critical values require homoskedastic disturbances, gives a critical value for the strength of the instruments. The Pagan-Hall statistic relates to the null of homoskedastic disturbances, and the Anderson-Rubin statistic relates to the null that all endogenous variables are jointly insignificant. 
that an instrument can be conceived as 'strong' if the first stage of the 2SLS routine delivers an $F$-statistic above 10 . In the case of one endogenous variable and three excluded instruments, this rule implies that the maximal size distortion on standard inference is less than 15\% (Stock and Yogo 2005, Table 2). In the present case, however, we are dealing with multiple endogenous variables, which means that the standard ruleof-thumb does not apply. A corresponding test, based on the Cragg-Donald statistic, can be performed in this case. The Cragg-Donald statistic is reported in Table 10(b), and must exceed the relevant critical value, which is derived in Stock and Yogo (2005), for instruments to be strong. ${ }^{34}$ In Table 10(b) the Cragg-Donald test statistic implies that we cannot reject that the size distortion is less than $20 \%$. By the rule-of-thumb standards, the causal effect of GADP and TRADE is therefore weakly identified. Consequently, we cannot trust standard tests of the individual significance of GADP or TRADE in explaining TFP, COMP1 and RES1.

Within the context of 2SLS we can, however, perform robust inference regarding joint significance using the Anderson-Rubin (1949) test, since it is fully robust to weak identification. The second from last row in Tables 10(a) and (b), tests the null of joint insignificance of the two endogenous variables. As is clear, we can reject that both GADP and TRADE are insignificant in the specifications involving TFP and COMPI; but we are unable to reject the null of joint significance in the case where RESI is the dependent variable. We can therefore conclude that institutions and integration (together, at least) causally affect the relative sectoral efficiency of the economy (as captured by COMPI), and through it aggregate $T F P$. We can pursue the matter further by implementing Limited Information Maximum Likelihood (LIML) estimation, which performs better in the context of weak instruments (Stock et al. 2002). For this reason the critical values are lower when the model is estimated by LIML instead of 2SLS (cf. Stock and Yogo 2005, table 4). When we conduct this exercise (not reported, but available upon request) we are able to control the problem of weak instrumentation to a level acceptable under the ruleof-thumb. We find that GADP is significant in explaining TFP and COMP1, but not RES1; moreover, TRADE is not significant. Once again, this suggests that at least institutions have a causal impact on COMP1, and through it on TFP.

In Table 11 we turn our attention to COMP2 and RES2. In the interest of brevity we report only the second-stage results, since the first-stage results are similar to those reported in Table 10(a). The instruments are the same and, although the sample is smaller, the measure of the composition term is arguably more satisfactory. In the full model, which includes controls for geography, the null of no over-identifying restrictions cannot be rejected. Moreover, in this set of regressions we are doing fine with respect to identification, by the rule-of-thumb standard. The main difference when compared with the results from Tables 10 (a) and (b) is that TRADE is now significant in the COMP2 specification. As before, neither TRADE nor GADP has an impact on RES. A more conservative conclusion, however, would be that we can reject joint insignificance of $T R A D E$ and GADP at least in the context of TFP and COMP2, but not in the context of $R E S 2$, as evident from the Anderson-Rubin test. ${ }^{35}$ As a result, the findings from Tables 10 and 11 are in accord with one another, even though different measures of relative intersectoral efficiency are invoked and the samples differ. Finally, even though institutions and international trade are jointly significant in explaining variations in $C O M P 2$, geographical factors are significant. In particular, in this limited sample we find that TROPICS now has a negative effect on $C O M P 2$, though it is not significant in explaining TFP or RES2. LANDLOCKED continues to be significant in explaining both TFP and COMP2.

(C) The London School of Economics and Political Science 2008 
TABLE 11

2SLS Regressions: Alternative Decomposition

\begin{tabular}{|c|c|c|c|c|c|c|}
\hline & \multicolumn{6}{|c|}{$\log (T F P) \log (T F P) \log (C O M P 2) \log (C O M P 2) \log (R E S 2) \log (R E S 2)$} \\
\hline & (1) & (2) & (3) & (4) & $(5)$ & $(6)$ \\
\hline \multirow[t]{2}{*}{$G A D P$} & $1.69^{* * * *}$ & $1.30^{* * * *}$ & $1.48^{* * * *}$ & $1.26^{* * * * *}$ & 0.22 & 0.05 \\
\hline & (3.77) & $(2.57)$ & $(4.27)$ & (3.63) & $(0.87)$ & $(0.11)$ \\
\hline \multirow[t]{2}{*}{$T R A D E$} & $0.34^{*}$ & 0.32 & 0.20 & $0.21^{* *}$ & 0.14 & 0.11 \\
\hline & $(1.71)$ & $(1.50)$ & $(1.44)$ & $(1.99)$ & $(1.14)$ & $(0.69)$ \\
\hline \multirow[t]{2}{*}{ TROPICS } & & -0.68 & & $-0.39^{*}$ & & -0.30 \\
\hline & & $(1.61)$ & & (1.83) & & $(1.05)$ \\
\hline \multirow[t]{2}{*}{ LANDLOCKED } & & $-0.55^{*}$ & & $-0.40^{*}$ & & -0.15 \\
\hline & & $(1.69)$ & & $(1.89)$ & & $(1.03)$ \\
\hline CONTINENTS & No & Yes & No & Yes & No & Yes \\
\hline Hansen $J$ statistic ( $p$-value) & 0.19 & 0.94 & 0.00 & 0.17 & 0.17 & 0.28 \\
\hline Cragg-Donald statistic & 13.23 & 7.06 & 13.23 & 7.06 & 13.23 & 7.06 \\
\hline Pagan-Hall ( $p$-value) & 0.17 & 0.64 & 0.05 & 0.15 & 0.39 & 0.80 \\
\hline $\begin{array}{l}\text { Anderson-Rubin statistic } \\
\quad(p \text {-value })\end{array}$ & 0.00 & 0.06 & 0.00 & 0.002 & 0.13 & 0.72 \\
\hline$N$ & 46 & 46 & 46 & 46 & 46 & 46 \\
\hline
\end{tabular}

Notes: All regressions contain a constant.

$*, * *, * * *$ Indicate significance at $10 \%, 5 \%$ and $1 \%$ respectively. Absolute $t$-values in parentheses; based on robust standard errors.

Excluded instruments: Eurfrac; Absolute latitude and fitted trade shares, as explained in the text.

Next, we change the set of instruments. These results are reported in Tables 12(a) and (b). From Table 12(a), we can observe that the settler mortality rates do a good job in accounting for variation in the GADP index, but not in TRADE. As argued in Acemoglu et al. (2002), we see that settler mortality rates do indeed seem to have a negative effect on institutional quality. As before, the geo-controls continue to play a limited role in explaining variations in these two measures. Table 12(b) reports the second-stage regressions. In this case too we have strong identification, in the sense that we can reject a size distortion above $15 \%$. Furthermore, we continue not to reject the nulls of no overidentifying restrictions, homoscedastic disturbances and joint insignificance of endogenous variables (the latter only in columns (1)-(4)). Thus, the significance of institutional quality continues to carry over, although the sample is now limited to countries that are colonized. However, note that the inclusion of geographic variables severely reduces the size of the estimated coefficient of GADP. Further, as in Table 10(b), both $L A N D L O C K E D$ and TROPICS are significant at $1 \%$ in explaining variations in TFP, with $L A N D L O C K E D$ also significant in explaining GADP. Overall, one can conclude that the general message of Tables 10 and 11 carries over. ${ }^{36}$

Finally, we turn to more specific measures of institutions: property rights, contracting institutions and financial development. The results are shown in Tables 13(a-c), which display the OLS results (Table 13(a)) and the IV results including the first stage (Tables 13(b) and (c)). In the interest of conserving space, the tables show only the point estimates of the various aspects of institutions, even though TRADE and a full set of the geo-controls are included in all the regressions. Briefly, we found that TRADE was insignificant in all cases, $L A N D L O C K E D$ was always significant for TFP, and COMP1

(C) The London School of Economics and Political Science 2008 
TABLE 12(a)

First Stage Regressions

\begin{tabular}{lcccc}
\hline & GADP & TRADE & GADP & TRADE \\
\cline { 2 - 5 } & $(1)$ & $(2)$ & $(3)$ & $(4)$ \\
\hline SETTLER MORTALITY & $-0.08^{* * * *}$ & -0.03 & $-0.1^{* * * *}$ & -0.03 \\
& $(5.31)$ & $(0.56)$ & $(4.31)$ & $(0.53)$ \\
$\log ($ AREA $)$ & $0.05^{* * * *}$ & 0.03 & $0.05^{* * * *}$ & 0.05 \\
& $(3.62)$ & $(0.78)$ & $(3.50)$ & $(1.33)$ \\
$\log ($ POP $)$ & $-0.03^{* * *}$ & $-0.25^{* * * *}$ & $-0.04^{* * *}$ & $-0.31^{* * * *}$ \\
& $(2.00)$ & $(2.67)$ & $(2.31)$ & $(6.07)$ \\
TROPICS & & & 0.10 & -0.05 \\
& & & $(1.29)$ & $(0.25)$ \\
LANDLOCK & & -0.05 & -0.38 \\
& & & $(0.96)$ & $(2.72)$ \\
CONTINENTS & No & No & Yes & Yes \\
$R^{2}$ & 0.49 & 0.33 & 0.48 & 0.47 \\
$N$ & 50 & 50 & 50 & 50 \\
\hline
\end{tabular}

Notes: All regressions contain a constant.

****,****Indicate significance at $10 \%, 5 \%$ and $1 \%$, respectively. Absolute $t$-values in parenthesis; based on robust standard errors.

TABLE 12(b)

2SLS Regressions: Alternative Instruments

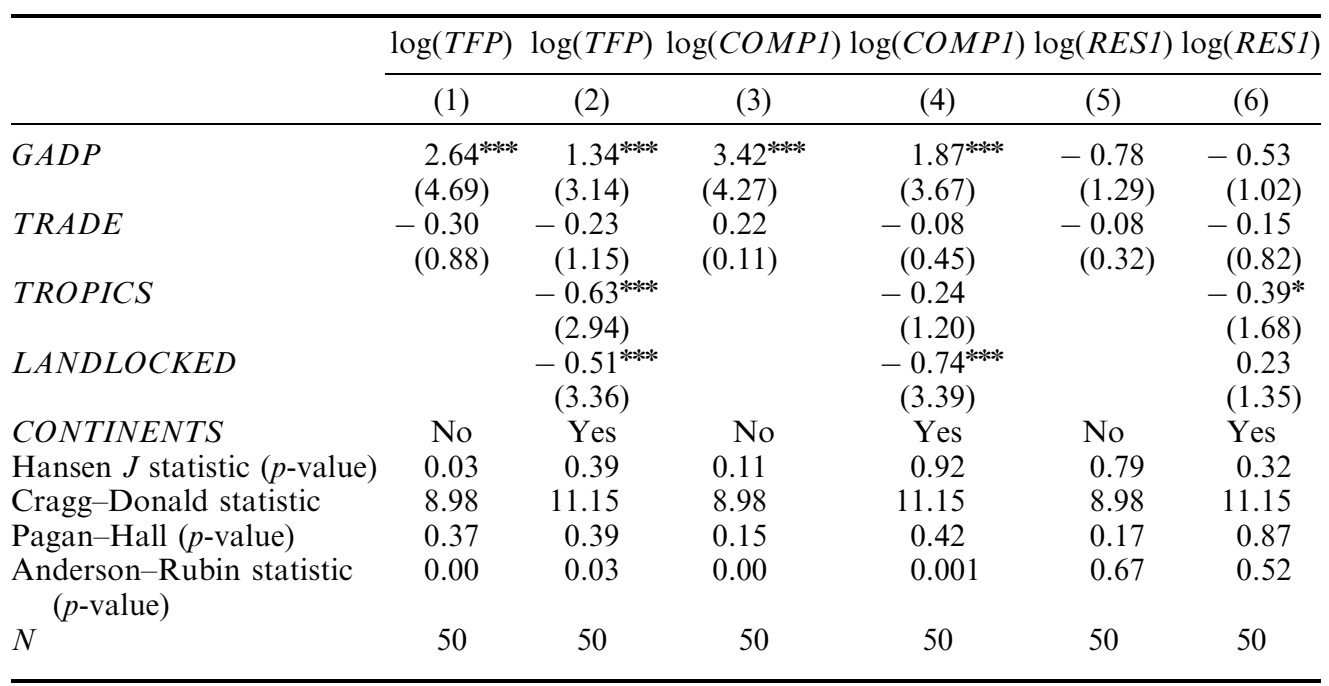

Notes: All regressions contain a constant.

$*, * *, * * *$ Indicate significance at $10 \%, 5 \%$ and $1 \%$ respectively. Absolute $t$-values in parentheses; based on robust standard errors.

Excluded instruments: Settler mortality rates; LogArea and LogPopulation, as explained in the text.

The Hansen $J$ statistic tests whether the exclusion restriction is valid; the null is that the instruments can be excluded from the second stage. The Cragg-Donald statistic, for which the critical values requires homoskedastic disturbances, gives a critical value for the strength of the instruments. The Pagan-Hall statistic relates to the null of homoskedastic disturbances, and the Anderson-Rubin statistic relates to the null that all endogenous variables are jointly insignificant. 
TABLE 13(a)

OLS - Alternative Institutional Measures

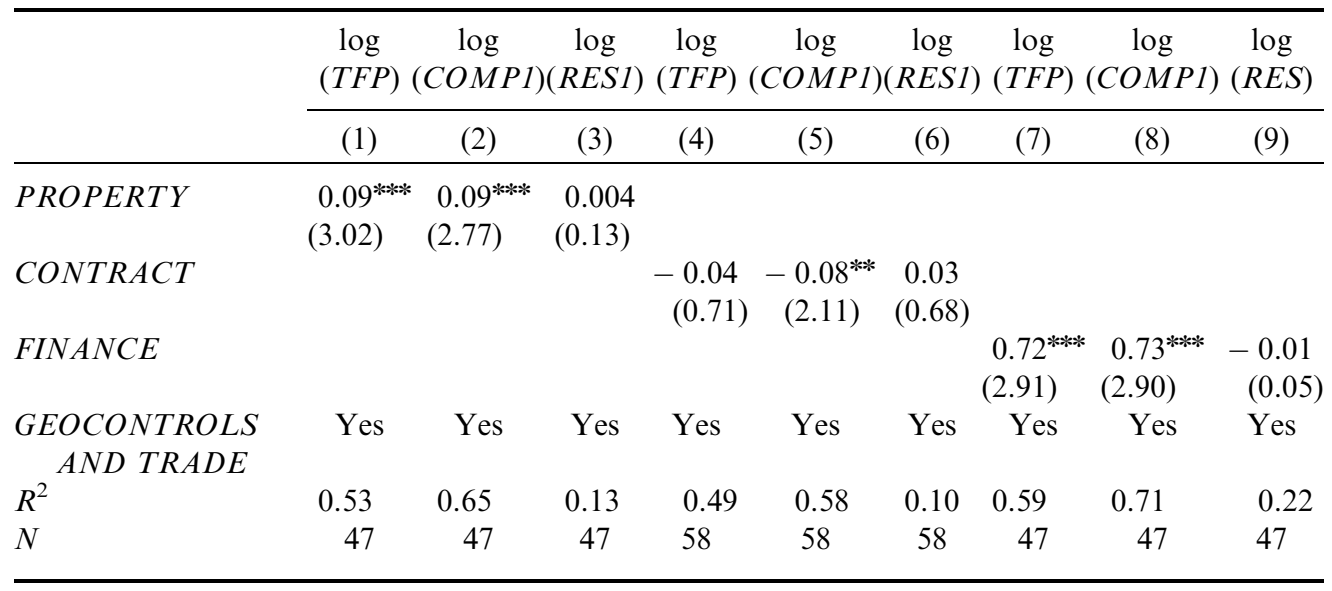

Notes: All regressions contain a constant.

$*, * *, * * *$ Indicate significance at $10 \%, 5 \%$, and $1 \%$, respectively.

Absolute $t$-values in parenthesis; based on robust standard errors.

TABLE 13(b)

First Stage Regressions

\begin{tabular}{lcccccc}
\hline & EXPR & TRADE & CONTRACT & TRADE & FINANCE & TRADE \\
\cline { 2 - 7 } & $(1)$ & $(2)$ & $(3)$ & $(4)$ & $(5)$ & $(6)$ \\
\hline SETTLER MORTALITY & $-0.74^{* * * *}$ & -0.04 & & & $-0.14^{* * * *}$ & -0.06 \\
& $(3.11)$ & $(0.59)$ & & & $(4.21)$ & $(0.96)$ \\
FRENCH LEGAL ORIGIN & & & $1.16^{* * * *}$ & 0.06 & & \\
& & & $(5.75)$ & $(0.61)$ & & \\
$\log ($ AREA $)$ & $0.55^{* * * *}$ & 0.02 & $-0.19^{* * *}$ & -0.04 & $0.04^{*}$ & 0.03 \\
& $(3.13)$ & $(0.54)$ & $(2.36)$ & $(1.07)$ & $(2.01)$ & $(0.89)$ \\
$\log ($ POP $)$ & $-0.38^{*}$ & $-0.29^{* * * *}$ & 0.14 & $-0.23^{* * * *}$ & -0.03 & $-0.31^{* * * *}$ \\
& $(1.80)$ & $(5.39)$ & $(1.49)$ & $(4.96)$ & $(1.07)$ & $(5.60)$ \\
GEOCONTROLS & Yes & Yes & Yes & Yes & Yes & Yes \\
$R^{2}$ & 0.41 & 0.50 & 0.60 & 0.57 & 0.47 & 47 \\
$N$ & 47 & 47 & 58 & 58 & 47 & 47 \\
\hline
\end{tabular}

Notes: All regressions contain a constant.

$*, * *, * * *$ Indicate significance at $10 \%, 5 \%$, and $1 \%$, respectively. Absolute $t$-values in parentheses; based on robust standard errors.

(at $1 \%$ for PROPERTY and FINANCE and $5 \%$ for CONTRACT), while TROPICS was significant at $1 \%$ for TFP and COMPl when the institutional controls were PROPERTY and CONTRACT but only for TFP when the control was FINANCE.

For instrumental variable estimation we employ the LIML estimator, which has better small-sample properties in the presence of weak instruments than the 2SLS estimator. Table 13(b) does not require much elaboration; the instruments for the various institutions are always significant. As in Table 12(a), the log of population (log POP) 
TABLE 13(c)

LimL Regressions: Alternative Institutional Measures

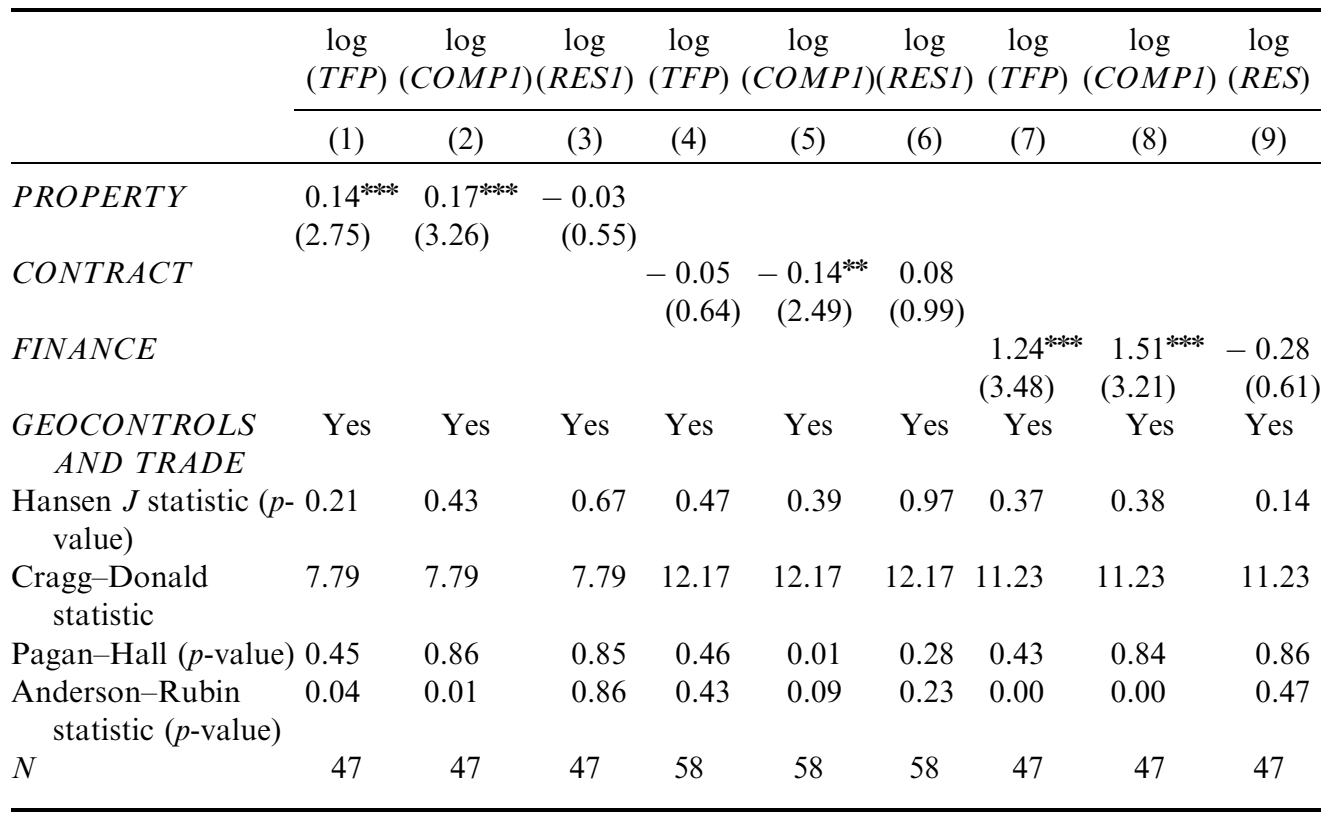

Notes: All regressions contain a constant.

$*, * *, * * *$ Indicate significance at $10 \%, 5 \%$ and $1 \%$, respectively. Absolute $t$-values in parentheses; based on robust standard errors.

Excluded instruments: Settler mortality rates; $\log (A R E A)$ and $\log (P O P U L A T I O N)$ in regressions involving Expropriation and Credit; French legal origin dummy, $\log (A R E A)$ and $\log (P O P U L A T I O N)$ in regressions involving legal formalism.

The Hansen $\mathbf{J}$ statistic tests whether the exclusion restriction is valid; the null is that the instruments can be excluded from the second stage. The Cragg-Donald statistic, for which the critical values require homoskedastic disturbances, gives a critical value for the strength of the instruments. The Pagan-Hall statistic relates to the null of homoskedastic disturbances, and the Anderson-Rubin statistic relates to the null that all endogenous variables are jointly insignificant.

predicts $T R A D E$ while $\log$ of area $(\log A R E A)$ seems to be more significant in predicting institutions rather than openness. Moving on to the second-stage regression, from the first three columns of Table 13(c), it is evident that PROPERTY has a strong impact on TFP and COMP1, whereas it does not have a significant impact on RES1. We also have strong identification in the sense that we can reject the hypothesis that the size distortion exceeds $10 \%$. These findings therefore strongly suggest (i) that property rights institutions, as measured by risk of expropriation, have a strong exogenous impact on measured aggregate $T F P$, and (ii) that this effect runs through relative sectoral levels of efficiency. Finally, though not shown here, $L A N D L O C K$ is again significant at the $1 \%$ level for TFP and COMP1, while TROPICS is significant at $2 \%$ and $1 \%$ for the two variables, respectively.

The next three columns deal with CONTRACT. Here the results are considerably weaker. While CONTRACT is significant in the COMP regression, and the CraggDonald test statistic is large enough to suggest strong identification, the critical values due to Stock and Yogo (2005) are potentially misleading, since we reject the null of homoscedastic residuals in the COMP regression. The Anderson-Rubin test is robust to 
both weak instruments and heteroscedasticity, however. But at the $10 \%$ level we cannot reject joint insignificance of both CONTRACT and TRADE. We are thus led to the conclusion that $C O N T R A C T$ is apparently less strongly related to macro efficiency levels than PROPERTY, which resonates well with the findings of Acemoglu and Johnson (2005). LANDLOCK and TROPICS however continue to be strongly significant in explaining both $T F P$ and $C O M P$.

The final three columns of Table 13(c) concern FINANCE. Once again, the entire impact from the institutional variable in question on $T F P$ seems to run via $C O M P$, not $R E S$. As seen from Table 13(b), settler mortality rates predict FINANCE well, leading to strong identification in the second stage. We reject that the size distortion is above $10 \%$. The result that FINANCE has a positive effect on relative sectoral efficiency is consistent with the priors, as is the view that financial development has a major impact on the productivity through facilitating an efficient allocation of capital across the sectors of the economy. Finally, LANDLOCK has a significantly negative effect on TFP and COMP1, while TROPICS is significant only for TFP.

Overall, these results provide strong support for the notion that institutions affect TFP through the dual economy channel, especially those dimensions of institutions related to the protection of property rights and financial development. In contrast, the impact of TRADE seems fragile. Finally, despite the recent evidence that institutions matter more than geography, we find that geographical variables too are important when explaining aggregate TFP differences, and also seem to be channelled via the dual economy path. In particular, we find that being landlocked seems to offer distinct disadvantages. On the other hand, being located in the tropics, while also consistently lowering aggregate $T F P$, does not seem to have a robust effect via the dual economy channel.

\section{CONCLUDING REMARKS}

Prescott's (1998) call for a theory of total factor productivity has been accompanied by a large body of research which attributes differences in output per worker to technological differences (often assumed to be the same as total factor productivity) generated by institutional barriers and, not unrelated, geographical factors, which hamper the adoption of socially profitable innovations.

As observed by Solow (cf. the quote in the Introduction), however, aggregate TFP differences may be highly affected by the process of structural change, and more generally by how efficiently economies allocate scarce inputs to individual sectors. In this paper we have tried to take this observation seriously, by asking whether variations in relative efficiency levels across sectors is of any quantitative importance vis-à-vis observed variation in aggregate productivity. Our analysis suggests that answer is in the affirmative. Specifically, we have demonstrated that a significant fraction of the observed variation in measured $T F P$ is attributable to the relative efficiency of sectors, and furthermore that relative efficiency levels are strongly affected by the institutional environment of individual economies, their geographic conditions and, to some extent, trade. In sum, it seems that, in order to provide a rigorous theory of cross-country total factor productivity differences, a theory of structural composition must be an important component. 


\section{APPENDIX: RE-NORMALIZING AGRICULTURE VALUE ADDED}

We follow the method suggested by Caselli (2005). The key observation is that, since PPP prices are quantity-weighted, they tend to resemble rich country prices. Accordingly, one may expect that the PPP agricultural share of GDP should be approximately equal to the nominal GDP share in the United States:

$$
\frac{p_{A, U S}^{P P P} Y_{A, U S}^{P P P}}{Y_{U S}^{P P P}} \approx \frac{p_{A, U S} Y_{A, U S}}{Y_{U S}} .
$$

In this expression, the RHS fraction (nominal share of agriculture) is available from World Development Indicators. The denominator on the LHS is PPP GDP from the Penn World Tables. Accordingly, we can solve for $p_{A, U S}^{P P P} Y_{A, U S}^{P P P}$ and derive the the scaling factor:

$$
s=\frac{p_{A, U S}^{P P P} Y_{A, U S}^{P P P}}{p_{A, U S}^{F A O} Y_{A, U S}^{F A O}}
$$

where the superscript FAO denotes the FAO numbers. Multiplying all FAO PPP numbers on agriculture value added by $s$ should make them comparable with PWT's GDP numbers for 1985 . With comparable PPP numbers on GDP and GDP in agriculture, we can calculate the nonagricultural GDP shares as well. Using employment shares $\left(\lambda_{a}, \lambda_{n a}\right)$ from World Development Indicators, we can compute PPP numbers on labour productivity in the two sectors, $y_{a}$ and $y_{n a}{ }^{37}$

\section{ACKNOWLEDGMENTS}

We are grateful to Francesco Caselli, Antonio Ciccone and Donald Larson for sharing their data, and for their comments. We would also like to thank two anonymous referees, Shekhar Aiyar, Oded Galor, Doug Gollin, Tom Grennes, Halvor Mehlum, Doug Pearce, John Seater, Jon Temple, Eric Thorbecke, Dietz Vollrath and seminar participants at the University of Copenhagen, the University of Malaga, the European Economic Association Meeting in Stockholm, Midwest Macro Meetings, The Nordic Conference in Development Economics in Copenhagen, Hebrew the University, Hunter College (CUNY), the University of Houston, Louisiana State University, North Carolina State University, Utah State University, the XV Villa Mondragone International Economic Seminar, 75 Years of Development Economics Conference at Cornell, and NEUDC, for their comments. We are responsible for all errors.

Part of this research was conducted while Carl-Johan Dalgaard was visiting the Universitat Pompeu Fabra Economics Department, the hospitality of which is gratefully acknowledged. The activities of EPRU (Economic Policy Research Unit) are financed through a grant from the Danish National Research Foundation. Earlier versions of this paper were circulated under the title 'Dual Economies and International TFP Differences'.

\section{NOTES}

1. This literature spawned a sizeable neoclassical growth literature on dual economies: see e.g. Jorgenson (1961), Dixit (1970), Mas-Colell and Razin (1973). More recent contributions include Laitner (2000), Gollin et al. (2002, 2004), and Banerjee and Duflo (2005).

2. See Temple (2005) for a survey.

3. Caselli (2005) and Cordoba and Ripoll (2006) assume efficient allocations, while Vollrath (2006) does not.

4. That is, if $h$ differs in the two sectors this would be isomorphic to differences in levels of $A$, which we started by ruling out.

5. See Felipe and Fisher (2003) for recent discussion of the existence of an aggregate production function. See also Cordoba and Ripoll (2006).

6. As we use $Y / L=T F P \cdot(K / Y)^{\alpha /(1-\alpha)}$ when deriving TFP, COMP would, technically speaking, correspond to the term in brackets raised to $1 /(1-\alpha)$. Likewise, $A^{1 /(1-\alpha)}=A_{n a}$.

7. Capital's share $\alpha$ is put at $1 / 3$.

8. The correlation between our TFP numbers for 1985 and HJ's own estimates for 1988 is 0.98 .

9. Recently these numbers have been used by Caselli (2005) and Restuccia et al. (2007) in their work on calculating agricultural sector TFP's. 
10. The aggregate fixed capital stock in their estimates is greater than the sum of fixed capital stocks in agriculture and manufacturing, leaving room for other sectors. That is, the three series are independent estimates; the first two use sector-specific investment rates while the aggregate estimate uses investment numbers for the entire economy.

11. Cordoba and Ripoll (2006) also extrapolate using UNESCO numbers and note that the correlation of their values with that of Vollrath is 0.996.

12. See Orazem (2006, figure 2).

13. The correlation between our implied average human capital per worker and HJ estimates of human capital per worker is 0.96 . However, their estimates exhibit slightly higher variation: the standard deviation in our case is 1.56 while in their estimates it is 2.03 .

14. Similar considerations naturally apply to covariances involving $K / Y$ and $T F P$. If externalities are present, capital accumulation may increase $T F P$. On the other hand, even a neoclassical growth model will predict a correlation between $A$ and $K / Y$, outside the steady state. As a result, the interpretation of the covariance between $K / Y$ and $T F P$ is unclear as well.

15. Klenow and Rodriguez-Clare (1997) (KRC) provide a decomposition approach that may seem different from the one above. However, the two decompositions are equivalent if the covariance term is split evenly between the two variances. To see this, note that var $(\ln (C O M P l))+\operatorname{cov}(\ln C O M P l), \ln$ $(R E S I)=\operatorname{cov}(\ln (T F P), \ln (C O M P l))$, and likewise var $(\ln (R E S I))+\operatorname{cov}(\ln (C O M P I)$, $(R E S 1))=\operatorname{cov}(\ln (T F P), \log (R E S 1))$, in which case the formula above becomes var $(\ln (T F P))=\operatorname{cov}$ $(\ln (T F P), \ln (R E S I))+\operatorname{cov}(\ln (T F P), \ln (C O M P 1)) ;$ the KRC decomposition.

16. Engerman and Sokoloff $(1997,2000)$ and Acemoglu et al. (2002) explain the variation (and 'reversal') in the quality of institutions in colonized nations as a consequence of the different natures of colonization. In particular, Acemoglu et al. focus on the role of the establishment extractive $v$. property rights institutions in colonies. Engerman and Sokoloff argue that the establishment of such institutions was a direct function of the returns to scale in agriculture and had consequences not just for the long-run quality of institutions but also for income distribution.

17. Our discussion in this section focuses on well known recent empirical contributions. Needless to mention, the intellectual literature on the role of institutions, trade and geography is far too voluminous for us to document here. Interested readers are referred to the cited works for further references.

18. A few contributions have examined which of these three hypotheses are more fundamental. Typically, institutions are found to be more fundamental; see Easterly and Levine (2003) and Rodrik et al. (2004). In contrast, however, Glaeser et al. (2004) argues that the institutional measures invoked in this sort of analysis are conceptually flawed and that they do not reflect the deep parameters they are purported to measure.

19. One could also imagine a 'channelling' analysis involving regressions on the remaining components of GDP per worker; $K / Y$ and $h$. Hall and Jones (1999) conducted this analysis, and found that the social infrastructure of an economy (which includes our GADP variable) influences both these factors. However, the association is particularly strong for $T F P$, which is the element we further examine below.

20. Our brief discussion of these theories is based on Acemoglu et al. (2002).

21. Despite the potential overlap, they note some key differences. First, weaknesses in contracting institutions between private parties can be circumvented (albeit at a higher cost) by designing alternate contracts or engaging in alternative occupations. On the other hand, property rights institutions are closely linked to the distribution of political power in society, and it is not possible to completely circumvent the state when writing contracts.

22. This measure is available only from 1982 onwards.

23. We use the average of two indices of legal formalism: the index of formality in legal procedures required for collecting a bounced check, and another for eviction of a residential tenant for non-payment of rent.

24. In this paper we make no attempt to 'unbundle' these aspects of institutions from one another, as is attempted in Acemoglu and Johnson (2005). That is, we run separate regressions for each measure and assess its impact on the LHS variable. Disentangling the impact of property rights on TFP from that of financial development is thus a matter for future research.

25. See e.g. Frankel and Romer (1999), and Rodrik et al. (2004).

26. Recall that our measure of $C O N T R A C T$ reflects legal complexity; a large value is therefore thought to be associated with 'bad' institutional outcomes.

27. For the sake of brevity, for the rest of the discussion COMP and RES will refer to the logarithms of the respective variables.

28. The correlation matrix involving COMP2 and RES2 is close to being identical to Table 7 . In the interest of conserving space, this correlation matrix is therefore omitted, but is available upon request.

29. For a description of how the third instrument is constructed, see either Frankel and Romer (1999) or Alcalá and Ciccone (2004). It should also be noted that Hall and Jones used, the fraction of the population speaking English as another instrumental variable; we ultimately dropped this variable, since keeping this variable in the set of instruments led to poor identification.

30. Briefly, the theory is that institutions conducive to private enterprise were put in place only where Europeans chose to settle down, which in turn were areas where settler mortality rates were fairly low. Since institutional infrastructure is highly persistent, the argument goes, bad institutions in the past will 
matter for outcomes today. A limitation of applying this instrument is that it restricts the sample to developing countries that were colonized by a European power. However, given the recent demonstrated influence of this variable on long-run development, we feel this is an important and worthwhile exercise.

31. Beck et al. (2003) distinguish between the 'law and finance theory' and the 'endowment theory'. The former theory suggests the use of legal-origin dummies as instruments, whereas the latter motivates the use of settler mortality rates. We also ran IV regressions using legal-origin dummies, instead of settler mortality rates. The results are similar, although we get less strong identification with the legal origin dummy variable. This conforms with the findings of Beck et al. (2003), who also find that the endowment theory of financial development explains more of the variation in the data than the law and finance theory.

32. The ones without geo-controls essentially mimic the exercises in Hall and Jones (1999).

33. An equivalent way of expressing the problem of weak instrumentation is to say that it leads the 2SLS estimator to be biased towards OLS.

34. Since Stock and Yogo assume homoscedasticity in deriving critical values, we have provided a test for the null of homoscedasticity in all tables (Pagan-Hall).

35. Recall that 'strong instruments' really means that the size distortion of associated inference is not 'too large'.

36. We also examined another variable, constraints on the executive, which, according to Glaeser et al. (2004), would be a de jure measure of property rights as opposed to risk against expropriation which is more of a de facto measure. While the OLS regressions suggested a significant effect, IV estimation did not produce significant test statistics and the Cragg-Donald statistic implied large size distortions even under LIML estimation.

37. While we have followed the methodology of Caselli, we have used PWT 5.6 whereas he uses PWT 6.1. Thus, the implied shares will still be different as the two versions have different base year: version 5.6 uses 1985 as the base year, which is particularly useful for us since all our calculations are done for 1985.

\section{REFERENCES}

Acemoglu, D. and Johnson, S. (2005). Unbundling institutions. Journal of Political Economy, 113, 949-95. and Robinson, J. A. (2001). The colonial origins of comparative development: an empirical investigation. American Economic Review, 91, 1369-1401.

and - (2002). Reversal of fortune: geography and institutions in the making of the modern world income distribution. Quarterly Journal of Economics, 117, 1231-94.

Aghion, P. and Griffith, R. (2005). Competition and Growth. Cambridge, Mass: MIT Press.

AlcalÁ, F. and Ciccone, A. (2004). Trade and productivity. Quarterly Journal of Economics, 119, $613-46$.

Anderson, T. and Rubin, H. (1949). Estimation of the parameters of a single equation in a complete system of stochastic equations. Annals of Mathematical Statistics, 20, 46-63.

Banerjee, A. and Duflo, E. (2005). Growth theory through the lens of development economics. In P. Aghion and S. Durlauf (eds.), Handbook of Economic Growth, Vol. 1A. Amsterdam: North-Holland.

Beck, T., Demirgüç-Kunt, A. and Levine, R. (2000). A new database on financial development and structure. World Bank Economic Review, 14, 597-605.

- - and (2003). Law, endowments, and finance. Journal of Financial Economics, 70, $137-81$.

BILs, M. and Klenow, P. (2000). Does schooling cause growth? American Economic Review, 90, $1160-82$.

CAselli, F. (2005). Accounting for cross-country income differences. In P. Aghion and S. Durlauf (eds.), Handbook of Economic Growth, Vol. 1A. Amsterdam: North-Holland.

CoE, D. and Helpman, E. (1995). International R\&D spillovers. European Economic Review, 39, 857-87.

CORDOBA, J. and RIPOLL, M. (2006). Agriculture, aggregation, wage gaps and cross country income differences. Working Paper, Rice University.

Crego, A., Larson, D., Butzer, R. and Mundlak, Y. (2000). A new database on investment and capital for agriculture and manufacturing. World Bank Economic Review, 14, 371-91.

Diamond, J. (1997). Guns, Germs and Steel. New York: W. W. Norton.

DiXit, A. (1970). Growth patterns in a dual economy. Oxford Economic Papers, 22, 229-34.

Djankov, S., La Porta, R., Lopez-De-Silanes, F. and Shleifer, A. (2003). Courts. Quarterly Journal of Economics, 118, 453-517.

EAsterly, W. and Levine, R. (2003). Tropics, germs, and crops: the role of endowments in economic development. Journal of Monetary Economics, 50, 3-39.

Engerman, S. L. and SokolofF, K. L. (1997). Factor endowments, institutions, and differential paths of growth among new world economies. In S. H. Haber (ed.), How Latin America Fell Behind. Stanford, Cal.: Stanford University Press. 
and - (2000). Institutions, factor endowments, and paths of development in the new world. Journal of Economic Perspectives, 14, 217-32.

FeliPE, J. and Fisher, F. M. (2003). Aggregation in production functions: what applied economists should know. Metroeconomica, 54, 208-62.

FISHER, F. (1978). Aggregate production functions revisited: the mobility of capital and the rigidity of thought. Review of Economic Studies, 49, 615-26.

Frankel, J. A. and Romer, D. (1999). Does trade cause growth? American Economic Review, 89, $379-99$.

Gallup, J., Sachs, J. and Mellinger, A. (1999). Geography and economic development. Working Paper no. 1, Center for International Development Harvard University.

Galor, O. and MountFord, A. (2006). Trade and the great divergence: the family connection. American Economic Review, 96, 229-303.

Glaeser, E., La Porta, R., Lopez-De-Silanes, F. and Shleifer, A. (2004). Do institutions cause growth? Journal of Economic Growth, 9, 271-303.

Gollin, D., Parente, S. and Rogerson, R. (2002). The role of agriculture in development. American Economic Review, Papers and Proceedings, 92, 160-64. and - (2004). Farm work, home work and international productivity differences. Review of Economic Dynamics, 7, 827-50.

Graham, B. and Temple, J. (2006). Rich nations, poor nations: how much can multiple equilibria explain? Journal of Economic Growth, 11, 5-41.

HALl, R. and JONES, C. I. (1999). Why do some countries produce so much more output per worker? Quarterly Journal of Economics, 114, 83-116.

HibBs, D. and Olsson, O. (2005). Biogeography and long-run economic development. European Economic Review, 49, 909-38.

Jorgenson, D. W. (1961). The development of a dual economy. Economic Journal, 71, 309-34.

King, R. and Levine, R. (1994). Capital fundamentalism, economic development and economic growth. Carnegie-Rochester Conference Series on Public Policy, 40, 259-92.

Klenow, P. J. and Rodriguez-Clare, A. (1997). The neoclassical revival in growth economics: has it gone too far? In B. Bernanke and J. J. Rotemberg (eds.), NBER Macroeconomics Annual. Cambridge and London: MIT Press, pp. 73-103.

KNACK, S. and KEEFER, P. (1995). Institutions and economic performance: cross-country tests using alternative institutional measures. Economics and Politics, 7, 207-27.

KRUEGER, A. O. (1968). Factor endowments and per capita income differences among countries. Economic Journal, 78, 641-59.

LAITNER, J. (2000). Structural change and economic growth. Review of Economic Studies, 67, 545-61.

LANDON-LANe, J. and Robertson, P. (2005). Barriers to accumulation and productivity differences in a two sector growth model. Mimeo, Rutgers University.

Leibenstein, H. (1960). Economic Backwardness and Economic Growth: Studies in the Theory of Economic Development. New York: John Wiley.

LEVINE, R. (2005). Finance and growth: theory and evidence. In P. Aghion and S. Durlauf (eds.), Handbook of Economic Growth, Vol. 1A. Amsterdam: North-Holland.

Mas-Colell, A. and Razin, A. (1973). A model of intersectoral migration and growth. Oxford Economic Papers, 25, 72-79.

Matsuyama, K. (1992). Agricultural productivity, comparative advantage and economic growth. Journal of Economic Theory, 58, 317-34.

Nelson, R. and Phelps, E. (1966). Investment in humans, technological diffusion and economic growth. American Economic Review, 56, 69-75.

North, D. C. (1990). Institutions, Institutional Change and Economic Performance. Cambridge: Cambridge University Press.

OraZEM, P. (2006) The benefits and costs of alternative strategies to combat illiteracy, Working Paper no. 6029, Iowa State University.

Prescott, E. (1998). Needed: a theory of total factor productivity. International Economic Review, 39, 525-51.

RAO, D. S. P. (1993). Intercountry comparisons of agricultural output and productivity. Social and Economic Development Paper, no. 112, Food and Agriculture Organisation, Rome.

RestuCCIA, D. (2004). Barriers to capital accumulation and aggregate total factor productivity. International Economic Review, 45, 225-38.

- YANG, D. and ZHU, X. (2007). Agriculture and aggregate productivity: a quantitative cross-country analysis. Working Paper, Univerity of Toronto. 
Rodrik, D., Subramanian, A. and Trebbi, F. (2004). Institutions rule: the primacy of institutions over geography and integration in economic development. Journal of Economic Growth, 9, 131-65.

Rose, A. (2006). Size really doesn't matter: in search of a national scale effect. Journal of the Japanese and International Economies, 20, 482-507.

Rosenstein-Rodan, P. (1943). Problems of industrialisation of eastern and south-eastern Europe. Economic Journal, 53, 202-11.

Rostow, W. (1961). Stages of Economic Growth: A Non-Communist Manifesto. Cambridge: Cambridge University Press.

Solow, R. (2001). What have we learned from a decade of empirical research on growth? Applying growth theory across countries. World Bank Economic Review, 15, 283-8.

STAIGER, D. and STOCK, J. (1997). Instrumental variables with weak instruments. Econometrica, 65, 557-86.

STOCK and Yogo, M. (2005). Testing for weak instruments in linear IV regression. In D. W. K. Andrews and J. H. Stock (eds.), Identification and Inference for Econometric Models: Essays in Honor of Thomas Rothenberg. Cambridge: Cambridge University Press, pp. 80-108.

Wright, J. and Yogo, M. (2002). A survey of weak instruments and weak identification in generalized method of moments. Journal of Business and Economic Statistics, 20, 518-29.

TEMPLE, J. (2005). Dual economy models: a primer for growth economists. Manchester School, 73, 435-78.

Timmer, P. (2002). Agriculture and economic development. In B. Gardner and G. Rausser (eds.), The Handbook of Agricultural Economics, Vol. 2A, Amsterdam: North-Holland.

UlubașoĞLU, M. A. and CARDAK, B. A. (2007). International comparisons of rural urban educational attainment: data and determinants. European Economic Review, 51, 1828-57.

Vollrath, D. (2006). Factor market imperfections and aggregate productivity in dual economies. Mimeo, University of Houston.

WORLD BANK (2006). World Development Indicators 2005. CD-ROM. Washington, DC: World Bank. 